\title{
An economic theory of foreign interventions and regime change
}

\author{
Roberto Bonfatti] University of Nottingham
}

\begin{abstract}
I construct a theory of foreign interventions in which a home country's main trade partner may influence the course of regime change. The foreign country intervenes in support of the group that draws the largest gains from trade, since such a group is willing to concede most in trade agreements. But interventions are more than offset by the domestic political system, which supports in power the group who concedes least (economic nationalism). I allow for geopolitical competition between the main trade partner and a second foreign country, as well as for domestic ideological preferences over the two, and look at how geopolitical competition interacts with the economic mechanism described above. My results help interpret some of the patterns of Western interventions in the 20th century, and the role of economic nationalism in regime change. Furthermore, they help explain why the Cold War strengthened the West's preference for incumbent elites, even when the oppositions did not have a strong communist ideology. I provide detailed historical evidence in favor of my arguments.
\end{abstract}

JEL codes: D7, F1, F5, N4, H25.

Corresponding author: Roberto Bonfatti, roberto.bonfatti@nottingham.ac.uk

\section{Introduction.}

The political economy literature has recently sought to understand the economic determinants of regime change, and particularly democratization. However, work on this topic has focused on the domestic determinants of regime change, whereas there has been very little work on the role of foreign interventions 11 Still, historical evidence suggests that foreign interventions played a key role in the 20th century. Cases such as Iran (1953), Guatemala (1954) and Chile (1973) are classical examples, but there are many more.

Looking at Western interventions in the 20th century, three interesting patterns stand out. First, the Western countries did not intervene at random around the world, but rather

I thank the editor, Hao Li, and two anonymous referees for many helpful comments, and Tim Besley, Robin Burgess, Toke Aidt, Walter Mattli, Gerard Padro-i-Miquel, Dan Seidmann and Davide Ticchi for useful comments. I also thank seminar participants at Oxford and the LSE, as well as conference participants at PEUK 2010, ISNIE 2010, and at the World Congress of the Econometric Society. Special thanks go to Nathan Nunn for providing the data on CIA interventions. All remaining errors are mine.

${ }^{1}$ A notable exception to this is the seminal paper by Aidt and Albornoz (2011), which I discuss in detail below. 
tended to focus on specific areas, often called their "spheres of influence." Second, Western interventions could often be rationalised by the fact that some domestic groups appeared more willing than others to treat foreign investments generously, and, geopolitically, to align themselves to the intervening country's camp. This calls into question why did some groups appear in such a way. Third, Western interventions often took place in countries where economic nationalism - the wish to concede less to foreign investors - played a very important role in motivating domestic revolutionaries, often as important as the redistributive motive emphasized by the literature on regime change.

I construct a theory that helps rationalise these and other interesting patterns from economic fundamentals. There is a home country, $H$, where a challenger $(c)$ can successfully rebel against an incumbent $(i)$ at a stochastic cost. To pre-empt this, $i$ can either surrender power, or unleash repression that makes revolution more costly. In the latter case, the country's main economic partner, $F$, and its geopolitical rival, $E$, may also intervene, to make revolution more or less costly. If $c$ goes to power, this leads to domestic redistribution. In addition, whoever ends up in power can negotiate a bilateral agreement with $F$. I see this as being mainly about the economy for $H$, mainly about geopolitics for $F$ : for example, the agreement may grant $H$ access to $F$ 's market for its exports, in exchange for $H$ 's geopolitical alignment to $F$. The agreement is not just signed, but negotiated: so, it may be that, to induce $F$ to sign, $H$ must concede rents to $F$ 's investors, or that, vice-versa, $F$ must pay aid to induce $H$ to sign. As an alternative to an agreement with $F, H$ may sign an agreement with $E$, but this is suboptimal for $H$ 's economy. Finally, I let $i$ and $c$ gain differently from an agreement (for example, they may be differently involved in international trade), and also have opposite ideological preferences over signing with $F$ versus $E$.

In this setting, both agents sign an agreement with $F$, unless they have a strong ideological aversion towards it. This makes $E$ uninterested in regime change, and thus unwilling to intervene. The first result, then, is that $H$ should be an exclusive sphere of influence of its main economic partner. Indeed, $F$ may intervene in $H$ in equilibrium, to support the agent who, gaining more from an agreement, is willing to concede more to secure one. This leads to a second result: involvement in the international economy determines which agent concedes more to F's investors, and can then benefit from F's support. A third result is that economic nationalism - the wish to concede less to foreign investors - should also be an important driver of regime change, beside redistribution. For example, if $c$ is the agent who concedes less to $F$, then revolution is more attractive to $c$, repression less attractive to $i$ : they both like to have someone in power who concedes little. Comparative statics reveal that the logic of the spheres of influence should become stronger in periods of greater geopolitical tension, when, by threatening to sign with $E, H$ can extract more of the value of an agreement with $F$. Furthermore, the weight of economic nationalism should increase with $H$ 's gains from an agreement, and with inequality in the distribution of the gains from an agreement.

I conclude by briefly outlining an extension fully developed in the working paper version of the paper (Bonfatti 2015). If rents conceded in the past are hard to re-negotiate (for example, because of reputation reasons), $i$ may have an incentive to unilaterally concede 
rents to $F$, in order to secure more of its support in future political disturbances. Intuitively, suppose $c$ is not ideological averse to $F$, and thus potentially interested in signing an agreement with this country. However, being relatively little involved in the international economy, she is not willing to concede major rents. Then, if $c$ goes to power, and finds that large existing rents cannot be easily re-negotiated in the context of an agreement with $F$, she may want to turn to an agreement with $E$ instead. The logic of the spheres of influence can then be broken, and $F$ must scale up its support for $i$. Comparative statics show that periods of greater geopolitical tension should be associated with more frequent interventions by $F$ against $c$, and with a lower probability of regime change, even if $c$ is not ideologically averse to $F$.

These results may help explain the three above-mentioned patterns of Western interventions. They may also help explain why, in quite a few countries - such as Cuba (1959), Nicaragua (1979), and Iran (1979) - regime change led to costly disruption in bilateral relations with key trade partners. Finally, they may explain why, during the Cold War, the West opposed, and effectively reversed, democratization in many developing countries, despite the fact that the groups who would benefit from it were not clearly communist. I discuss this historical evidence in an overview in Section 4, and in a few country studies in Online Appendix A (available on the author's website).

The paper contributes to the political economy literature on democratization. This can be organized into two main strands. The first focuses on redistribution as a driver for democratization (e.g. Acemoglu and Robinson 2006), while the second shows that it may be economically profitable for the ruling group to share power with a broader set of citizens (e.g. Lizzeri and Persico 2004) ${ }^{2}$ I borrow the basic structure of the model from papers in the first group, but innovate by looking specifically at the case of foreign interventions.

To the best of my knowledge, the only other paper to have attempted this before is Aidt and Albornoz (2011) ${ }^{3}$ They look at the transition from elite rule to democracy, when the elite, owning domestic capital that is complementary in production with foreign capital, can be trusted to tax foreign investors less than the workers, and the country where foreign capital originates can intervene to keep the elite in power. My paper differs from Aidt and Albornoz (2011) in two key respects. First, I consider a different mechanism that makes one group (not necessarily the economic elite) want to concede more rents than the other: while they emphasize ownership of domestic capital that is complementary to foreign capital, I look at dependence on an agreement with a foreign government. Second, I additionally look at how geopolitical alignment is endogenous to regime change, in the context of geopolitical competition between two foreign powers. Because of these differences, my paper generates

\footnotetext{
${ }^{2}$ For a detailed discussion of the literature on democratization, the interested reader is referred to Acemoglu and Robinson (2006). Alternatively, a very concise review of the literature using formal modeling can be found in Ticchi and Vindigni (2008).

${ }^{3}$ Less related are two papers that consider how exogenous features of the outside world may affect the probability of regime change. Acemoglu et al. (2010) focus on the role of the army in regime change, and look at the impact of an external threat on the political equilibrium. Aidt, Albornoz and Gassebner (2012) consider the case in which new regimes are granted welcome aid packages from foreign donors, and these may exogenously differ depending on whether the new regime is a democracy or an autocracy.
} 
a series of novel results; it has a different empirical focus than Aidt and Albornoz (2011); and it provides an alternative (or complementary) interpretation of some of their historical evidence. I discuss these innovations in further detail throughout.

The paper is also related to an empirical literature that studies the determinants and consequences of Cold War CIA and KGB interventions. Easterly, Satyanath and Berger (2008; ESB) look at the impact of these interventions on democracy, and find this to be negative in both the short and the long run. Dube, Kaplan and Naidu (2011) provide evidence of unusual stock trading in American companies that would soon benefit from classified CIA interventions, hinting at a close involvement of America's top corporate echelons in US foreign interventions. Finally, Easterly, Nunn, Satyanath and Berger (2010; ENSB) find that countries intervened in by the CIA went on to import more from the US, a sign that such interventions gave the US a good degree of influence over those countries. My results are consistent with the findings of these three papers, and, as I explain in more detail below, may help to interpret some of them $4^{4}$

The paper is organized as follows. I present the model in Section 2, and solve for the equilibrium in Section 3. Section 4 uses the model to interpret some of the patterns of foreign interventions in the 20th century, referring to Online Appendix A for case studies. Section 5 concludes, and discusses two possible extensions.

\section{Model.}

There is a home country, $H$, whose political regime is determined in a game with four players: two domestic agents (an incumbent, $i$, and a challenger, $c$ ), and two foreign countries $(F$ and $E)$. Agents $i$ and $c$ can be interpreted as the "elite" and the "citizens" as in Aidt and Albornoz (2011), but the model is more general. I interpret $H$ as a small developing country, and $F$ and $E$ as large developed countries. The game has two building blocks: a model of regime change, and a model of international agreements.

\subsection{Regime change.}

While $i$ is initially in power, $c$ can stage a revolution. This is costly to $c$ (more details below) but always successful at overthrowing $i$. Before $c$ decides whether to stage a revolution or not, $i$ can pre-empt this decision by surrendering power. I assume that, if $i$ is indifferent between surrendering power or not, it always surrenders it. If $c$ goes to power - be it through revolution or the surrender of power - redistribution takes place: $i$ owns a share $\theta_{i}$ of national income until he is in power, a share $\theta_{c} \leq \theta_{i}$ after $c$ goes to power (throughout the paper, I use subscripts to denote who is in power). I take the extent of redistribution, $\theta_{i}-\theta_{c}$, to be exogenously given, and to capture the degree of appropriability of $i$ 's income.

Revolution entails two costs for $c$. First, there is an exogenous cost, which is chosen by Nature and borne by $c$ upon staging a revolution. Using a standard notation in the

\footnotetext{
${ }^{4}$ Less related is a literature studying the efficiency implications of cross-border lobbying for domestic trade policy formation (Endoh 2005; Aidt and Hwang 2008; Antras and Padro-i-Miquel 2011), which does not consider the possibility of endogenous regime change.
} 
literature, I denote this cost by $\mu$. The cost $\mu$ captures all exogenous factors (such as the existence of a charismatic leader) that determine the severity of a group's collective action problem, and thus the difficulty with which it can rebel. It is drawn from a distribution with p.d.f. $f($.$) and c.d.f. F($.$) , taking a value over the interval [\underline{M}, \bar{M}]$ (with $\underline{M}<0$ and $\bar{M}>0$, and $|\underline{M}|,|\bar{M}|$ large). The negative portion of the support may capture the existence of non-economic benefits from regime change, such as the achievement of redistributional justice or of ethnic or religious goals.

Second, there is an endogenous cost of revolution, proportional to investment in repression by $i$, and to investment in foreign interventions by $F$ and $E$. If $i$ invests $m$ in repression (at a cost $|m|$ ), and $F$ and $E$ invest $m^{F}$ and $m^{E}$ in foreign interventions (at a cost $\left|m^{F}\right|$ and $\left.\left.\left|m^{E}\right|\right)\right\}^{5}$ the cost borne by $c$ upon staging a revolution becomes $\mu+m+m^{F}+m^{E}$. In equilibrium, it will always be $m \geq 0$, but it may be $m^{F} \gtreqless 0$ and $m^{E} \gtreqless 0$ : in other words, $i$ will only want to invest to make revolution harder (hence the term 'repression'), whereas $F$ and $E$ may want to intervene both to make it harder and to facilitate it. A positive $m$ could capture the purchase of military equipment, the deployment of extra security forces, or any other action that makes it harder for $c$ to stage a revolution. A positive $m^{J}$ (with $J \in\{F, E\}$ ) could capture a case in which $J$ supplies military equipment to $i$, a negative $m^{J}$ one in which $J$ supplies this to $c$.

\subsection{International agreements.}

There is an international agreement that $H$ can sign to increase its national income. In particular, $H$ 's national income is worth 1 if the country signs no agreement, but $1+\gamma$ (with $\gamma>0$ ) if it signs an agreement with $F$. Such an agreement is also worth $\gamma^{F}>0$ to $F$. I interpret the agreement as having mainly economic value for $H$, but also geopolitical value for $F$. For example, the agreement could grant $H$ access to $F$ 's market for its agricultural exports, in return for $H$ 's geopolitical alignment to $F$. The latter may consist in, for example, adopting a certain voting pattern in the UN, or conceding territory for $F$ 's military purposes. As an alternative to an agreement with $F, H$ can sign an agreement with $E$. Without loss of generality, $E$ is less good an economic partner for $H$; for simplicity only, an agreement with $E$ has no value for $H$. Such an agreement has, however, value $\gamma^{E}>0$ for $E$, which I also interpret as geopolitical value. So, $F$ and $E$ can be interpreted as geopolitical competitors, in the sense that $H$ 's agreement with one of the two reduces the potential payoff to the other. I focus on the case $\gamma^{E} \leq \gamma^{F}$ : $H$ is at least as geopolitically important to its main economic partner, than it is to the third country.

If an agreement between $H$ and $J \in\{F, E\}$ is signed, a transfer $r$ (from $H$ to $J$ ) can be used to redistribute the value of the agreement between the two. A positive $r$ may be interpreted as rents that $H$ grants to $J$ 's investors, a negative $r$ as aid that $J$ pays. Examples of rents are preferential concessions in the exploitation of natural resources, or in accessing $H$ 's consumer market. An increase in $r$ by one unit results in a unit gain for $J$, but in a cost $\phi \geq 1$ for $H$ : this allows for distortionary rents, or for a credit-constrained

\footnotetext{
${ }^{5}$ I consider in Online Appendix B2 (available on the author's website) the possibility that repression and foreign interventions have a convex, rather than linear, cost.
} 
$H$ (to whom aid is worth more than it costs). I assume that $i$ and $c$ share the costs or benefits of $r$ equally (and thus more equally than they share national income). This is a reasonable assumption, given that many of the government policies affected by the transfer will be redistributive in nature. For example, preferential mineral concessions may subtract resources to the provision of public goods, or to the funding of poverty-alleviation programs. Alternatively, preferential access for foreign investors may result in a higher cost of living for everyone, hitting particularly hard on the poor. Of course, the assumption that $\phi r$ is shared equally is just for simplicity: all that matters is that it is shared more equally than national income.

I also allow for ideological (non-economic) preferences over the signing of an agreement with $F$ versus $E$ : $i$ reports an extra benefit $\xi$ from signing with $F$, whereas $c$ reports an extra cost $-\xi$. For example, in a Cold-War setting, with $F$ representing the US and $E$ the USSR, $\xi>0$ would capture the case of a pro-capitalist incumbent and a pro-communist challenger, $\xi<0$ would capture the opposite.

The opportunity to sign an agreement presents itself after it has been decided who rules over $H$, and after any redistribution. The procedure to sign an agreement is as follows. First, the ruling agent negotiates with $F$ (a la Nash, with equal bargaining power) over a transfer to be implemented if an agreement between $H$ and $F$ is signed. If negotiations succeed, the agreement is signed, and the transfer implemented. If negotiations fail, the agent moves on to negotiations with $E$. These follow the same procedure as negotiations with $F$, except that if they fail, no further negotiations take place (and $H$ signs no agreement).

\subsection{Gross payoffs.}

Payoffs (gross of any cost of revolution, repression and foreign interventions) are a function of who ends up in power, as well as of any agreement signed and the related transfer. Let $W_{q}^{j}$ denote the gross payoff to agent $j \in\{i, c, F, E\}$ when agent $q \in\{i, c\}$ ends up in power. Consider first agent $i$. If an agreement with $F$ is signed, his payoff is:

$$
W_{q}^{i}=\theta_{q}(1+\gamma)+\xi-\phi \frac{r_{q}^{F}}{2},
$$

where $r_{q}^{F}$ denotes the transfer granted by agent $q$ to $F$. The cost of the transfer, $-\phi r_{q}^{F}$, is divided by two, to reflect the assumption that it is shared equally between $i$ and $c$. If instead an agreement with $E$ is signed, $i$ 's payoff is:

$$
W_{q}^{i}=\theta_{q}-\phi \frac{r_{q}^{E}}{2}
$$

where $r_{q}^{E}$ is the transfer granted by $q$ to $E$. Finally, if no agreement is signed, $i$ 's payoff is simply $W_{q}^{i}=\theta_{q}$. Next, consider agent $c$. If an agreement with $F$ is signed, her payoff:

$$
W_{q}^{c}=\left(1-\theta_{q}\right)(1+\gamma)-\xi-\phi \frac{r_{q}^{F}}{2} .
$$


If instead an agreement with $E$ is signed:

$W_{q}^{c}=1-\theta_{q}-\phi \frac{r_{q}^{E}}{2}$

If no agreement is signed, her payoff is $W_{q}^{c}=1-\theta_{q}$.

Finally, consider the payoff to $J \in\{F, E\}$. If $H$ signs an agreement with $J$, such payoff is:

$$
W_{q}^{J}=\gamma^{J}+r_{q}^{J}
$$

while if $H$ signs an agreement with $-J$, or if it signs no agreement, then $W_{q}^{J}=0$.

For domestic agents, regime change may imply up to three policy changes. The first is redistribution, what the literature on regime change has so far focused on. The second involves international agreements: $i$ and $c$ may choose different alignments. The third involves the terms of an agreement: given a choice of alignment, $i$ and $c$ may negotiate different $r$. For $F$ and $E$, the last two policy changes are all that matters.

\subsection{Timing.}

The game has four stages. All actions are observed by everyone immediately after they are taken.

1. Cost of revolution, surrender of power: Nature picks $\mu$. Subsequently, $i$ decides whether to surrender power or not.

2. Repression and foreign interventions: if $i$ has surrendered power, nothing happens. Otherwise, $i, F$ and $E$ sequentially ${ }^{6}$ set $m, m^{F}$ and $m^{E}$.

3. Revolution: if $i$ has surrendered power, nothing happens. Otherwise, $c$ decides whether to stage a revolution or not.

4. Redistribution, international agreement: if $c$ is in power, redistribution takes place. Otherwise, no redistribution takes place. Subsequently, negotiations for an agreement take place. Finally, all payoffs realise.

\section{Analysis.}

I look for the Subgame Perfect Equilibrium (SPE) of the game. This approach may seem inconsistent, given that the Nash bargaining solution used to characterise the outcome of stage 4 is a co-operative concept. However the justification for this approach is that, as well-known (e.g. Mothoo 1999), the Nash bargaining solution can be rationalised as the

\footnotetext{
${ }^{6}$ One interpretation for why $F$ moves before $E$ is that $H$ solicits foreign interventions from its main economic partner first. I thank an anonymous referee for suggesting this. I discuss in Online Appendix B1 the possibility that $i, F$ and $E$ move simultaneously.
} 
outcome of a non co-operative Rubinstein-style bargaining game, in which the discount factor goes to one. In particular, the specific Nash bargaining solution used in this paper is equivalent to that of a sequence of two limiting Rubinstein-style games - the first between the ruling agent and $F$, the second between the ruling agent and $E$ - with the ruling agent's payoff in the latter game being treated as her disagreement payoff in the former game.

An alternative specification would be to treat the ruling agent's payoff from an agreement with $E$ as her outside option in negotiations with $F$. While in the current specification such payoff always matters for the outcome of negotiations with $F$ (as shown below), in that alternative specification it would merely generate a constraint on the minimum payoff that the ruling agent must obtain in negotiations with $F$. Then, it would matter for the outcome of negotiations with $F$ only when the constraint is binding. One problem with that alternative specification is that it relies on the assumption that the ruling agent can credibly opt out of negotiations with $F$, to start negotiations with $E$. Given that $F$ is $H$ 's natural counterpart in an agreement, and given that international relations may take time to establish, this assumption may not be the most realistic. For this reason, I stick to the first specification. However, I show in Online Appendix B that results are qualitatively robust to adopting the alternative specification. In particular, the comparative statics described below is unchanged $[7$

\subsection{Stage 4. Redistribution, international agreements.}

Suppose first that $c$ has gone to power. Redistribution takes place. Then, $c$ enters into negotiations for an agreement. I begin by assuming that negotiations with $F$ fail, and find the outcome of negotiations with $E$. I then find the outcome of negotiations with $F$, using the outcome of negotiations with $E$ as $c$ 's disagreement payoff.

Negotiations between $c$ and $E$ must succeed. This is because an agreement between the two is joint-welfare increasing, and there exists a tool $\left(r_{c}^{E}\right)$ that the two can use to redistribute the value of the agreement between themselves. Because the agreement is valuable only to $E$, one would expect that this country will have to accept a negative transfer (pay aid) if an agreement is to be signed. In fact, the Nash bargaining solution transfer is:

$$
r_{c}^{E}=\arg \max _{r}\left(-\phi \frac{r}{2}\right)\left(\gamma^{E}+r\right)=-\frac{\gamma^{E}}{2},
$$

which is negative. The maximand is the product of c's gain from an agreement and $E$ 's gain. 8 Intuitively, the agreed-upon transfer is more negative, the more geopolitically important is $H$ (the higher $\gamma^{E}$ ): so, a country in a strategic position, or endowed with strategic natural resources, is predicted to receive more aid. It is easy to see that $c$ 's gain from an agreement is $\phi \frac{\gamma^{E}}{4}$.

\footnotetext{
${ }^{7}$ I thank the Editor, Hao Li, and an anonymous referee for useful suggestions on this point.

${ }^{8}$ Nash (1950) showed that if parties 1 and 2 negotiate over the choice of a utility vector $\left(u_{1}, u_{2}\right)$ from a convex set $U$, the unique solution having some desirable properties is $\arg \max _{\left(u_{1}, u_{2}\right) \in U}\left(u_{1}-d_{1}\right)\left(u_{2}-d_{2}\right)$, where $d_{1}$ and $d_{2}$ are disagreement utilities.
} 
Turning now to negotiations with $F$, these must fail if $c$ 's ideological aversion is so strong that an agreement between the two is joint-welfare decreasing. This happens if:

$$
\left(1-\theta_{c}\right) \gamma-\xi-\phi \frac{-\gamma^{F}}{2}<\phi \frac{\gamma^{E}}{4}
$$

On the left-hand side is c's gain from an agreement, if $F$ surrenders its entire gain $\left(r_{c}^{F}=-\gamma^{F}\right)$. On the right-hand side is $c^{\prime}$ s disagreement payoff. If the condition holds, there is no way that $F$ can induce $c$ to sign an agreement, and negotiations must fail. The condition can be re-written as:

$$
\xi>\left(1-\theta_{c}\right) \gamma+\phi\left(\frac{\gamma^{F}}{2}-\frac{\gamma^{E}}{4}\right) \equiv \bar{\xi} .
$$

Notice that $\bar{\xi}>0$ : it takes a degree of ideological aversion for negotiations with the country's main economic partner to fail.

If $\xi>\bar{\xi}$, negotiations with $F$ must fail. If $\xi=\bar{\xi}$, they can at best leave both parties as well off as at their disagreement point: I assume that they fail in this case as well. If $\xi<\bar{\xi}$ negotiations with $F$ must succeed. To find their outcome, recall that $c$ has disagreement payoff $\phi \frac{\gamma^{E}}{4}$. The Nash bargaining solution transfer then is:

$$
\begin{aligned}
r_{c}^{F} & =\arg \max _{r}\left[\left(1-\theta_{c}\right) \gamma-\xi-\frac{r}{2}-\phi \frac{\gamma^{E}}{4}\right]\left[\gamma^{F}+r\right] \\
& =\frac{\left(1-\theta_{c}\right) \gamma-\xi}{\phi}-\frac{\gamma^{F}}{2}-\frac{\gamma^{E}}{4} .
\end{aligned}
$$

The maximand in the first row is the product of $c$ 's gain from an agreement and F's gain, relative to a situation where $c$ signs an agreement with $E$. The second row reports the agreed-upon transfer. As simple algebra shows, the transfer is such that $c$ and $F$ split the value of the agreement in half. Then, $c$ concedes more, the more she gains from an agreement (the higher $\left(1-\theta_{c}\right) \gamma$ ), and the less important is $H$ to $F$ (the lower $\gamma^{F}$ and $\gamma^{E}$ ). This is intuitive: you would expect a ruler who is very involved in trade, and who sits in a geopolitically irrelevant country, having to concede a lot to secure an agreement.

In summary, $c$ signs with $F$ if $\xi<\bar{\xi}$, negotiating the transfer indicated in equation ??. If instead $\xi \geq \bar{\xi}$, she signs with $E$, negotiating the transfer indicated in equation ??. It can be shown that the transfer negotiated by $c$ decreases continuously in $\xi$ over $(-\infty, \bar{\xi})$, turning from positive to negative: quite intuitively, the more $c$ is ideologically averse to $F$, the less she concedes. It then jumps up at $\bar{\xi}$, as $c$ switches to a more ideologically attractive agreement with $E$.

Policy if $i$ has remained in power can be derived symmetrically. If:

$$
\xi \leq-\theta_{i} \gamma-\phi\left(\frac{\gamma^{F}}{2}-\frac{\gamma^{E}}{4}\right) \equiv \underline{\xi},
$$


$i$ signs an agreement with $E$, negotiating a transfer:

$$
r_{i}^{E}=-\frac{\gamma^{E}}{2}
$$

If instead $\xi>\underline{\xi}$, he signs an agreement with $F$, negotiating a transfer:

$$
r_{i}^{F}=\frac{\theta_{i} \gamma+\xi}{\phi}-\frac{\gamma^{F}}{2}-\frac{\gamma^{E}}{4}
$$

Symmetrically to the one negotiated by $c$, the transfer negotiated by $i$ jumps down at $\underline{\xi}$, and then increases continuously in $(\underline{\xi}, \infty)$, turning from negative to positive. It is easy to see that $\bar{\xi}>0, \underline{\xi}<0$.

Comparison of $i$ 's and c's policy reveals some intuitive patterns. When ideology is moderate, $\xi \in(\underline{\xi}, \bar{\xi})$, both agents stick to the country's main economic partner. However, if $i$ 's share of national income is high both before and after regime change $\left(\theta_{i}\right.$ and $\theta_{c}$ are high), he tends to concede more. Intuitively, high $\theta_{i}$ and $\theta_{c}$ imply that $i$ goes to the bargaining table having to gain more than $c$ from an agreement, while the two share the costs or benefits of the transfer equally. It is then not surprising that $i$ is willing to concede more to secure an agreement. Similarly, $i$ tends to concede more than $c$ if he is relatively more affine to $F$ (high $\xi$ ). Two interesting results stand out. First, if $i$ 's share of national income remains high after regime change (high $\theta_{c}$ ), even a small ideological aversion makes $c$ sign with $E$, since $\bar{\xi}$ is small. Second, if $H$ becomes more geopolitically important (a scaling up of $\gamma^{F}$ and $\gamma^{E}$ ), it becomes more likely for it to be aligned to $F$, since $(\underline{\xi}, \bar{\xi})$ expands. What drives the latter result is that $H$ can play the two foreign countries against each other only in the first stage of negotiations (by threatening to sign with the other if negotiations fail), and the first stage is assumed to be with the country's main economic partner. If $H$ becomes more important, the value of signing at the first stage, and thus with $F$, increases. This result suggests that periods of geopolitical tension should result in a tightening of alliances based on economic relations.

I introduce the following parametric assumption:

Assumption 1. $\left(1-\theta_{c}\right) \gamma, \theta_{i} \gamma>\phi\left(\frac{\gamma^{F}}{2}+\frac{\gamma^{E}}{4}\right)$.

Assumption 1 narrows the focus of the paper to the historically relevant case in which $H$ (a developing country) is more dependent on an agreement with $F$ (a developed country) than the other way around. In other words, $\gamma$ is large relative to $\gamma^{F}$ and $\gamma^{E}$. It implies that, if ideology is moderate, both $i$ and $c$ concede rents to $F: r_{c}^{F}>0$ and $r_{i}^{F}>0$.

Substituting the above-derived policies into equations ?? to ??, we obtain gross payoffs as a function of parameters. Let $\Delta W^{i} \equiv W_{c}^{i}-W_{i}^{i}$ and $\Delta W^{c} \equiv W_{c}^{c}-W_{i}^{c}$ denote gains from regime change to $i$ and $c$ respectively. In equations ?? to ??, I write these in a format that highlights the three possible policy changes associated with regime change. The first change, captured by the term $\left(\theta_{i}-\theta_{c}\right)(1+\gamma)$, is redistribution. It makes regime change 
attractive for $c$, and unattractive for $i$. The second change refers to the fact that $i$ and $c$ may choose different alignments, and is captured by the underlined terms. It appears only when ideology is extreme, because $i$ and $c$ both stick to $F$ when ideology is moderate. The third change refers to the fact that $i$ and $c$ may concede different $r$, and is captured by the terms in square brackets (which are equal to $\phi \frac{r_{i}-r_{c}}{2}$ ). It makes regime change more attractive for everyone, the more $i$ concedes relative to $c$. This difference is larger the larger are $i$ 's ex-ante and ex-post income shares, $\theta_{i}$ and $\theta_{c}$. It is easy to see that $r_{i}-r_{c} \geq 0$ if and only if $\xi>\frac{1-\theta_{i}-\theta_{c}}{2} \gamma$, the threshold level of ideology that offsets any difference in the two agents' gains from an agreement. Absent ideology $(\xi=0)$, the condition for $i$ to concede more is simply $\theta_{i}+\theta_{c}>1$.

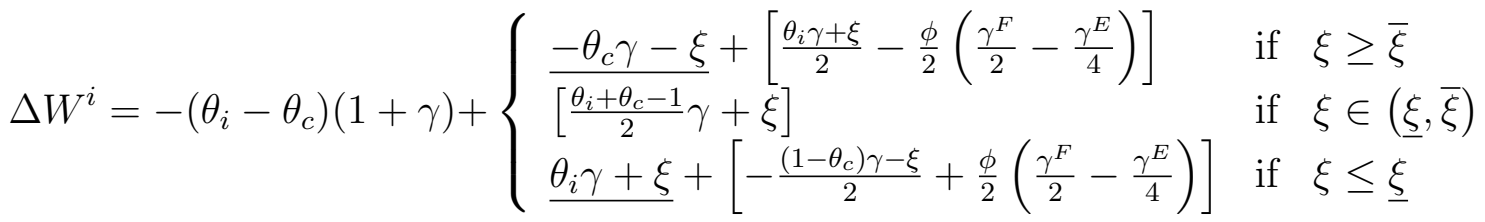

$$
\begin{aligned}
& \Delta W^{c}=\left(\theta_{i}-\theta_{c}\right)(1+\gamma)+\left\{\begin{array}{ll}
\frac{-\left(1-\theta_{c}\right) \gamma+\xi}{\left[\frac{\theta_{i}+\theta_{c}-1}{2} \gamma+\xi\right]}\left[\frac{\theta_{i} \gamma+\xi}{2}-\frac{\phi}{2}\left(\frac{\gamma^{F}}{2}-\frac{\gamma^{E}}{4}\right)\right] & \text { if } \xi \geq \bar{\xi} \\
\frac{\left(1-\theta_{i}\right) \gamma-\xi}{}+\left[-\frac{\left(1-\theta_{c}\right) \gamma-\xi}{2}+\frac{\phi}{2}\left(\frac{\gamma^{F}}{2}-\frac{\gamma^{E}}{4}\right)\right] & \text { if } \xi \in(\underline{\xi}, \bar{\xi})
\end{array} .\right.
\end{aligned}
$$

Figure 1 (panel a) illustrates. For $\xi=0$, both $\Delta W^{i}$ and $\Delta W^{c}$ are larger than redistribution would justify. That is because $i$ gains more from an agreement than $c$ (the figure assumes $\theta_{i}+\theta_{c}>1$ ) and thus concedes higher rents. As $\xi$ increases and $i$ becomes more relatively affine to $F$, the difference in rents increases, and $\Delta W^{i}$ and $\Delta W^{c}$ also increase. For $\xi$ very large, $\Delta W^{i}$ drops, because $i$ dislikes being derailed from an agreement with $F$ if $c$ goes to power.

Figure 1 ideally here.

Before continuing, I introduce a second parametric assumption:

Assumption 2. $\theta_{i}-\theta_{c}>\frac{\gamma+\phi\left(\gamma^{F}-\frac{\gamma^{E}}{2}\right)}{2+\gamma}$.

Assumption 2 requires redistribution to be a prominent driver of regime change, so that $\Delta W^{i}<0$ and $\Delta W^{c}>0$ always (proof of this is online Appendix B4). If redistribution was small, $i$ could be better off with $c$ in power if $c$ was able to concede a lower transfer.

I similarly derive the gains from regime change to $F$ and $E, \Delta W^{F} \equiv W_{c}^{F}-W_{i}^{F}$ and $\Delta W^{E} \equiv W_{c}^{E}-W_{i}^{E}$, and write them in equations ?? to ??. Changes in alignment and $r$ are all that matters for the two foreign countries. As before, the change in alignment is captured by the underlined terms, and appears only for extreme ideology. It makes regime 
change less (more) attractive for the country that the new regime switches away from (to). The change in $r$ is captured by the terms in square brackets, which, for $J \in\{F, E\}$, are equal to $r_{i}^{J}-r_{c}^{J}$. It makes regime change less attractive, the more $i$ concedes relative to $c$. Figure 1 (panel b) illustrates. For $\xi=0, \Delta W^{F}<0$, since $i$ concedes more than $c$. As $\xi$ increases and $i$ becomes more relatively affine to $F$, this pattern is magnified. For moderate ideology, regime change does not matter for $E$, since both agents stick to $F$. For $\xi$ large, however, $\Delta W^{E}$ jumps up, as regime change results in a switch in alignment from $F$ to $E$. Notice that $\Delta W^{E}>0$ implies $\Delta W^{F}<0$, and $\Delta W^{E}<0$ implies $\Delta W^{F}>0$. Thus, when both countries have strict preferences over regime change, these are opposite.

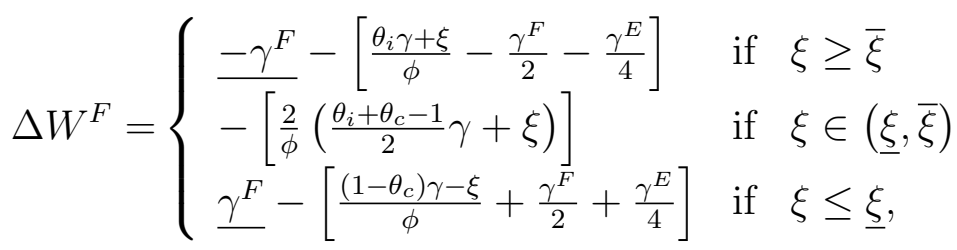

$$
\begin{aligned}
& \Delta W^{E}= \begin{cases}\frac{\gamma^{E}}{0}-\left[\frac{\gamma^{E}}{2}\right] & \text { if } \xi \geq \bar{\xi} \\
-\gamma^{E}-\left[-\frac{\gamma^{E}}{2}\right] & \text { if } \xi \in(\underline{\xi}, \bar{\xi}) .\end{cases}
\end{aligned}
$$

Summing across equations ?? to ??, I obtain the global gain from regime change, $\Delta W$ (equation ??). Redistribution, which is just a transfer from $i$ to $c$, does not matter for "global preferences" over regime change. In contrast, any change in alignment (the underlined terms) matters: for example, it makes regime change less attractive when $\xi \geq \bar{\xi}$. This is because regime change leads to a globally inefficient switch in alignment to $E$. Finally, any change in $r$ may also matter (the terms in square brackets are equal to $(\phi-1)\left(r_{i}-r_{c}\right)$ ). It does so when $\phi>1$, or rents are distortionary, since it is then efficient for the agent who concedes more not to end up in power. The heavy line in Figure 2 illustrates. For $\xi=0$, $\Delta W>0$, since $i$ concedes more than $c$, and rents are assumed to be distortionary. As $\xi$ increases and $i$ becomes more relatively affine to $F$, the difference in rents increases, and $\Delta W$ also increases. However, for $\xi$ very high, $\Delta W$ drops, since regime change results in an inefficient switch in alignment to $E$.

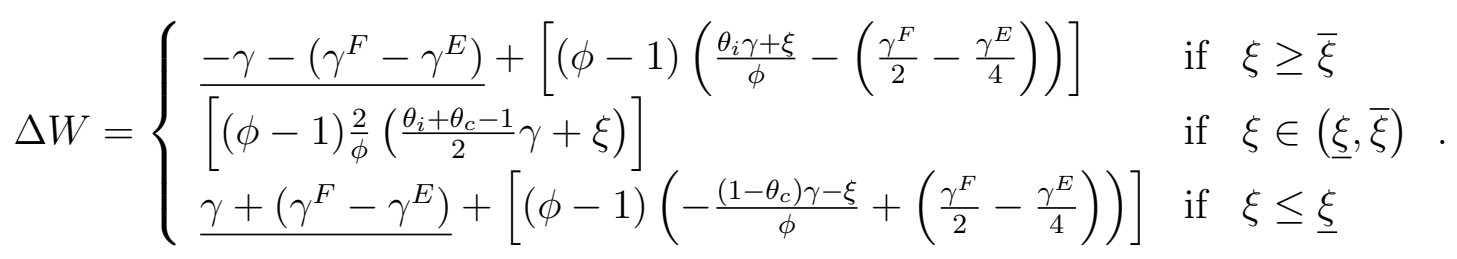

This discussion highlights that, beside redistribution, there are two new forces behind regime change. The first, which I call economic nationalism, refers to the fact that $i$ and $c$ like to concede as little as possible to foreign countries. It shapes domestic preferences in favor of the strongest negotiator. If rents are distortionary, it even shapes global preferences in favor of this agent. The second force, which I call international disruption, refers to the 


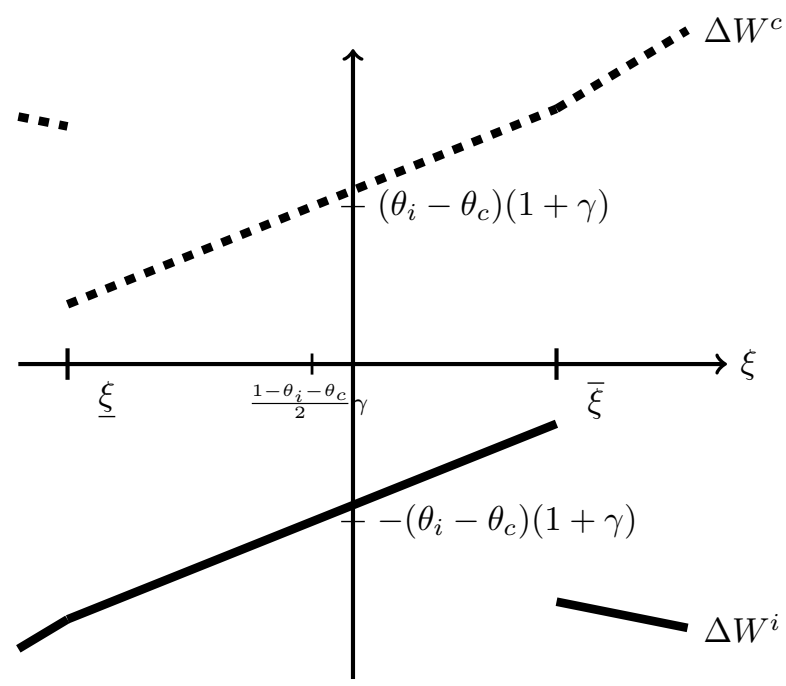

(a)

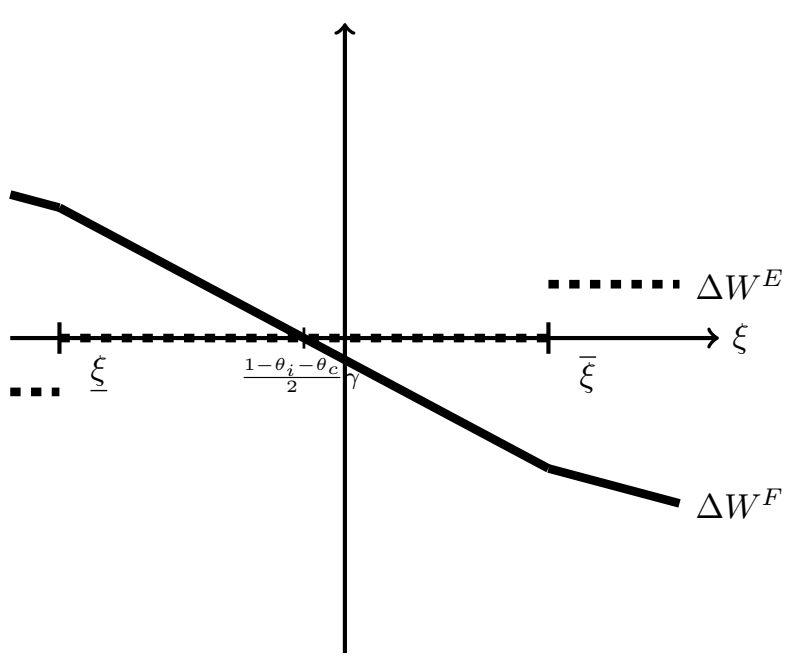

(b)

FIGURE 1 Gains from regime change when $\theta_{i}+\theta_{c}>1, \phi>1$.

fact that regime change may sidetrack $H$ from its efficient pattern of international relations. It shapes global preferences against the agent who would sign with $E$.

\subsection{Stage 3. Revolution.}

If $i$ has surrendered power in stage 1, nothing happens. Otherwise, $c$ decides whether to stage a revolution or not. It is optimal for $c$ to stage a revolution if her cost is smaller than her gain:

$$
\mu+m+m^{F}+m^{E}<\Delta W^{c}
$$

Condition ?? proposes a modified version of Acemoglu and Robinson (2006)'s revolution constraint. As in that model, revolution is a threat when $c$ 's exogenous cost of revolution, as increased by repression $(\mu+m)$, is smaller than her gain from redistribution (included in $\left.\Delta W^{c}\right) \cdot 9$ There are two new elements: foreign interventions $\left(m^{F}+m^{E}\right)$, and the fact that $\Delta W^{c}$ also depends on economic nationalism and international disruption.

\subsection{Stage 2. Repression and foreign interventions.}

If $i$ has surrendered power, nothing happens. Otherwise, $i, F$ and $E$ sequentially decide how much to invest in repression and foreign interventions. Given these investments, if condition ?? holds, $c$ stages a revolution. However, in equilibrium, $c$ may stage a revolution also if $\mu+m+m^{F}+m^{E}=\Delta W^{c}$. For this reason, I now describe the SPE of the entire subgame that starts after $i$ has not surrendered power. I relegate the full description of the SPE

\footnotetext{
${ }^{9}$ Repression is modelled by Acemoglu and Robinson (2006) in a different, but substantially equivalent way.
} 
to the Appendix, and describe here only the equilibrium paths. Unless otherwise stated, proofs are also in the Appendix.

LEMMA 1. If $i$ does not surrender power in stage 1, one equilibrium path is as follows:

- Stage 2. If $\xi \geq \frac{1-\theta_{i}-\theta_{c}}{2} \gamma$ (so that $\Delta W^{F} \leq 0, \Delta W^{E} \geq 0$ ), $i, F$ and $E$ set:

$$
\left(m, m^{F}, m^{E}\right)= \begin{cases}(0,0,0) & \text { if } \mu>\Delta W^{c, E} \\ \left(0, \Delta W^{c, E}-\mu, 0\right) & \text { if } \mu \in\left(\Delta W^{c, F, E}, \Delta W^{c, E}\right] \\ \left(\Delta W^{c, F, E}-\mu,-\Delta W^{F}, 0\right) & \text { if } \mu \in\left(\Delta W, \Delta W^{c, F, E}\right] \\ (0,0,0) & \text { if } \mu \leq \Delta W\end{cases}
$$

where $\Delta W^{c, E} \equiv \Delta W^{c}+\Delta W^{E}$ and $\Delta W^{c, F, E} \equiv \Delta W^{c}+\Delta W^{F}+\Delta W^{E} ;$ if instead $\xi<\frac{1-\theta_{i}-\theta_{c}}{2} \gamma$ (so that $\left.\Delta W^{F}>0, \Delta W^{E} \leq 0\right)$, they set:

$$
\left(m, m^{F}, m^{E}\right)= \begin{cases}(0,0,0) & \text { if } \mu>\Delta W^{c, F, E} \\ \left(\Delta W^{c, F, E}-\mu, 0,0\right) & \text { if } \mu \in\left(\Delta W, \Delta W^{c, F, E}\right] \\ \left(0, \Delta W^{c, E}-\mu, 0\right) & \text { if } \mu \leq \Delta W \text { and } \mu \geq \Delta W^{c, E} \\ (0,0,0) & \text { if } \mu \leq \Delta W \text { and } \mu<\Delta W^{c, E}\end{cases}
$$

- Stage 3. c stages a revolution if $\mu \leq \Delta W$, does not stage a revolution otherwise;

and the game then moves to the bargaining phase of stage 4. For $\mu \neq \Delta W$, such a path is unique. For $\mu=\Delta W$, there exists only one other, which is as follows. Stage 2: if $\xi \geq \frac{1-\theta_{i}-\theta_{c}}{2} \gamma,\left(m, m^{F}, m^{E}\right)=\left(-\Delta W^{i},-\Delta W^{F}, 0\right)$, if $\xi<\frac{1-\theta_{i}-\theta_{c}}{2} \gamma,\left(m, m^{F}, m^{E}\right)=$ $\left(-\Delta W^{i}, 0,0\right)$; Stage 3: $c$ does not stage a revolution; and the game than moves to the bargaining phase of stage 4 .

The equilibrium paths described in Lemma 1 make intuitive sense. To illustrate, consider, for example, the first path, and focus on the case $\xi>\frac{1-\theta_{i}-\theta_{c}}{2} \gamma\left(\right.$ when $\left.\Delta W^{F}<0, \Delta W^{E} \geq 0\right)$. If $\mu>\Delta W^{c, E}$, Nature's cost of revolution is higher than the joint gain from regime change to $c$ and $E$. Then, revolution never occurs, not even if $i$ and $F$ do not repress/intervene. Anticipating this, $i$ and $F$ do not repress/intervene, $E$ does not intervene, and $c$ does not stage a revolution. If $\mu \in\left(\Delta W, \Delta W^{c, E}\right]$, Nature has made revolution jointly optimal for $c$ and $E$, but still costly enough that $i$ and $F$ can profitably block it (by increasing its cost to $\left.\Delta W^{c, E}\right) 10$ There are two subcases. If $\mu \in\left(\Delta W^{c, F, E}, \Delta W^{c, E}\right]$, Nature's cost of revolution is high enough that, even by itself, $F$ can profitably block a revolution. Anticipating this, $i$ does not repress, forcing $F$ to intervene. If $\mu \in\left(\Delta W, \Delta W^{c, F, E}\right]$, Nature's cost of revolution is too low for $F$ to be able to block it by itself, and $i$ must repress. However, he invests the minimum required amount, still forcing $F$ to intervene. Finally, if $\mu \leq \Delta W$, Nature's cost

\footnotetext{
${ }^{10}$ I show in the Appendix (Proposition A1) that, given these actions by $i$ and $F$, it is an equilibrium requirement that either $c$ does not stage a revolution when at a tie (implying that it is strictly optimal for $E$ to set $m^{E}=0$ ), or that $c$ does stage a revolution when at a tie, but $E$ sets $m^{E}=0$ when at a tie. In either cases, the actions of $i$ and $F$ are enough to block a revolution.
} 
of revolution is so low that $i$ and $F$ cannot profitably block it. They then neither repress nor intervene, and $c$ stages a revolution (with no need for $E$ 's intervention) 11

This first path is unique if $\mu \neq \Delta W$, but not if $\mu=\Delta W$. Intuitively, in the latter case, $i$ is indifferent between repressing or not, since successful repression costs exactly as much as regime change. There are then two paths: one in which $c$ does not repress (and $c$ stages a revolution) and one in which $i$ represses (and $c$ does not stage a revolution).

Lemma 1 suggests that, if $i$ does not surrender power, revolution happens if it is efficient $(\mu<\Delta W)$. On reflection, this makes sense. All agents are represented in the decision on revolution, be it directly, as $c$, or indirectly through repression and foreign interventions, as $i, F$ and $E$. The linear investment technology then ensures that the revolution decision is efficient.

\subsection{Stage 1. Cost of revolution, surrender of power.}

Faced with Nature's choice of $\mu, i$ decides whether to surrender power or not. In doing so, he anticipates that, if he does not surrender power, the subgame that follows features the equilibrium described in Lemma 1. The equilibrium path of the overall game is unique, and is described in the following proposition (the full description of the SPE is in the Appendix):

Proposition 1. On the unique equilibrium path, if $\mu \leq \Delta W$, $i$ surrenders power in stage 1, and the game moves directly to the bargaining phase of stage 4. If instead $\mu>\Delta W$ :

- Stage 1. $i$ does not surrender power;

- Stage 2. If $\xi \geq \frac{1-\theta_{i}-\theta_{c}}{2} \gamma$ (so that $\Delta W^{F} \leq 0$ and $\Delta W^{E} \geq 0$ ), i, F and $E$ set:

$$
\left(m, m^{F}, m^{E}\right)= \begin{cases}(0,0,0) & \text { if } \mu>\Delta W^{c, E} \\ \left(0, \Delta W^{c, E}-\mu, 0\right) & \text { if } \mu \in\left(\Delta W^{c, F, E}, \Delta W^{c, E}\right] \\ \left(\Delta W^{c, F, E}-\mu,-\Delta W^{F}, 0\right) & \text { if } \mu \in\left(\Delta W^{c} \Delta W^{c, F, E}\right]\end{cases}
$$

If instead $\xi<\frac{1-\theta_{i}-\theta_{c}}{2} \gamma$ (so that $\Delta W^{F}>0$ and $\left.\Delta W^{E} \leq 0\right)$, they set:

$$
\left(m, m^{F}, m^{E}\right)=\left\{\begin{array}{ll}
(0,0,0) & \text { if } \mu>\Delta W^{c, F, E} \\
\left(\Delta W^{c, F, E}-\mu, 0,0\right) & \text { if } \mu \in\left(\Delta W, \Delta W^{c, F, E}\right]
\end{array} ;\right.
$$

- Stage 3. c does not stage a revolution;

and the game then moves to the bargaining phase of stage 4.

In equilibrium, $i$ surrenders power if and only if $\mu \leq \Delta W$. Intuitively, if $\mu>\Delta W$ and $i$ holds on to power, $c$ does not stage a revolution, and, if any repression is needed, this costs less than $-\Delta W^{i}$. Instead, if $\mu \leq \Delta W$ and $i$ holds on to power, either $c$ stages a

\footnotetext{
${ }^{11}$ Intuitively, E's intervention would have been necessary for a revolution only if $i$ and $F$ had repressed/intervened.
} 
revolution, or (only if $\mu=\Delta W$ ) the revolution is staved off at a cost $-\Delta W^{i}$ in repression. Consistently with the lack of a political Coase theorem, the mechanism that regulates the political transition is inefficient: if $\Delta W>0$, it would be efficient for all parties to agree on peaceful regime change. Still, peaceful regime change does not happen if $\mu \leq \Delta W$.

Notice that, if $\mu \leq \Delta W, i$ is, strictly speaking, indifferent between surrendering power or not. It is then only because of the tie-breaking rule introduced in Section 2.1 that he surrenders power. That tie-breaking rule implies that, in equilibrium, regime change always happens through the surrender of power: in other words, revolution never happens. This simplifying feature is common to similar models of regime change (see Acemoglu and Robinson 2006, Ch. 6). It would be straightforward to modify the tie-breaking rule so that, in equilibrium, regime change could happen through both the surrender of power and revolution. If $i$ 's tie-breaking rule was to surrender power with probability $p \in[0,1]$, regime change would still happen when $\mu \leq \Delta W$. However, when it would happen, it would be through revolution with probability $p$, through the surrender of power with probability $1-p$. It is easy to see that the comparative statics discussed below would still hold true for the probability of regime change, but it would also separately apply to the probability of revolution, and to the probability of the surrender of power.

To interpret Proposition 1, suppose $H$ is a Latin American country in the mid 20th century, $i$ an incumbent elite, $c$ the citizens, and $F$ and $E$ the US and USSR respectively. Consider first a benchmark scenario in which the international forces discussed in this paper are inactive: international agreements are not important for the domestic economy $(\gamma \rightarrow 0)$, the superpowers do not care about $H^{\prime}$ 's geopolitical alignment $\left(\gamma^{F}, \gamma^{E} \rightarrow 0\right)$, and domestic agents are not ideological $(\xi=0)$. The following corollary describes the equilibrium in this benchmark scenario:

Corollary 1. If $\gamma, \gamma^{F}, \gamma^{E} \rightarrow 0$ and $\xi=0$, the equilibrium path converges to the following. If $\mu \leq 0$, $i$ surrenders power in stage 1 , and the game moves directly to the bargaining phase of stage 4 . If instead $\mu>0$ :

- Stage 1. $i$ does not surrender power;

- Stage 2. i, F and E set:

$$
\left(m, m^{F}, m^{E}\right)= \begin{cases}(0,0,0) & \text { if } \mu>\theta_{i}-\theta_{c} \\ \left(\theta_{i}-\theta_{c}-\mu, 0,0\right) & \text { if } \mu \in\left(0, \theta_{i}-\theta_{c}\right]\end{cases}
$$

- Stage 3. c does not stage a revolution;

and the game then moves to the bargaining phase of stage 4.

Proof. Follows immediately from Proposition 1 and equations ?? to ??, since $\Delta W \rightarrow 0$, $\frac{1-\theta_{i}-\theta_{c}}{2} \gamma \rightarrow 0, \Delta W^{F} \rightarrow 0, \Delta W^{c, E}, \Delta W^{c, F, E} \rightarrow \Delta W^{c}$, and $\Delta W^{c} \rightarrow \theta_{i}-\theta_{c}$. 


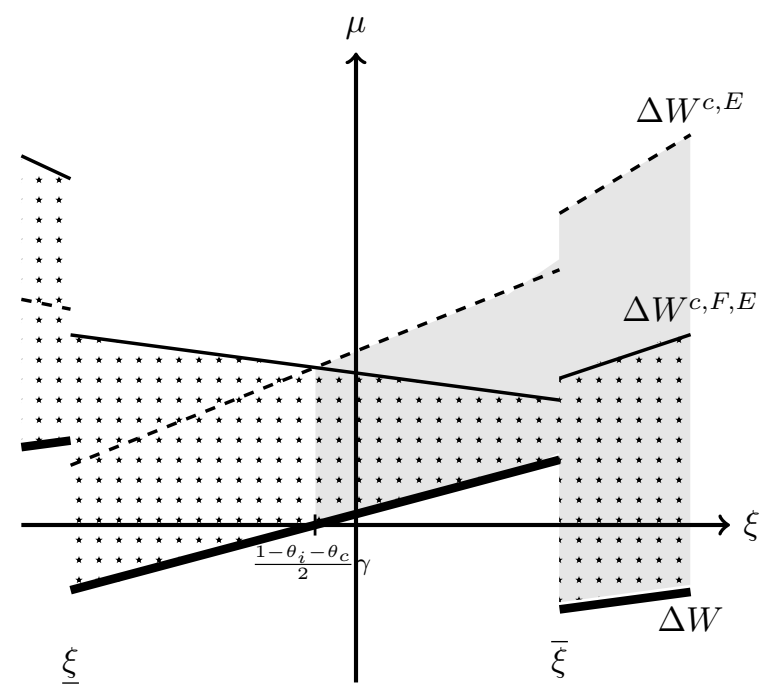

FIGURE 2 Political equilibrium when $\theta_{i}+\theta_{c}>1, \phi>1$

In the benchmark scenario, redistribution is the only force behind regime change. In equilibrium, regime change happens if and only if Nature gives the citizens a low enough cost of revolution $(\mu \leq 0)$. Otherwise, the elite can successfully hold on to power, using repression if needed (if $\left.\mu \in\left(0, \theta_{i}-\theta_{c}\right]\right)$. One interesting finding is that higher redistribution (higher $\theta_{i}-\theta_{c}$ ) does not make regime change more likely. This is because higher inequality makes both revolution and repression more attractive, and these two forces cancel out in equilibrium. This result is a special case of a similar result in Acemoglu and Robinson (2006): see their Corollary 6.1, where inequality is found to have a non-monotonic relationship with the likelihood of regime change. Notice also that the superpowers refrain from interfering in the country's political transition.

Now re-introduce international forces. In addition, suppose that the elite are landowners who, even after redistribution, are more involved than the citizens in exporting to the US $\left(\theta_{i}+\theta_{c}>1\right)$, and that the citizens may be relatively more "leftist" (on top of their preference for redistribution) compared to the elite $(\xi \geq 0)$. Figure 2 represents the equilibrium. Since $\xi \geq 0$, we focus on the right-hand portion of the diagram. As in the benchmark case, regime change happens if and only if Nature gives the citizens a low enough cost of revolution $(\mu \leq \Delta W)$. However, regime change is more likely than in the benchmark case if the citizens are moderate leftists (since $\Delta W>0$ ), less likely if they are extremists (since $\Delta W<0$ ). Intuitively, in the former case, the citizens are as good as the elite at foreign policy - they efficiently sign with the US - but, being tougher negotiators, are able to negotiate a better deal with the US government. Economic nationalism, then, makes regime change more likely. In the latter case, the citizens cannot be trusted with foreign policy, since they inefficiently sign with the USSR. Economic nationalism notwithstanding, then, the fear of international disruption makes regime change less likely.

Figure 2 ideally here. 
A look at equation ?? sheds light on the comparative statics of regime change. Changes in parameters that increase $\Delta W$ make regime change more likely, and vice-versa. Redistribution, $\theta_{i}-\theta_{c}$, still does not matter for regime change, at least directly. However, higher ex-ante and ex-post income shares of the incumbent (higher $\theta_{i}$ or $\theta_{c}$ ) make the citizens more likely to end up in power, because they boost economic nationalism. Then, we get the surprising result that a higher $\theta_{c}$, which ceteris paribus means lower redistribution, is associated with a higher probability of regime change. Next, a greater importance of international agreements (a scaling up of $\gamma$ ) makes moderate citizens more likely to end up in power, because it boosts economic nationalism. However, because it also boosts the fear of international disruption, it makes extremist citizens less likely to end up in power. Finally, a greater geopolitical importance of $H$ (a scaling up of $\gamma^{F}, \gamma^{E}$ ) makes extremist citizens less likely to end up in power. Intuitively, a greater prominence of international relations benefits a challenger who can be trusted with foreign policy, penalises a challenger who cannot.

If the elite holds on to power, it may do so using repression (in the starred area) and/or US interventions (in the gray area). If the citizens are moderate, the US supports the elite for purely economic reasons: it benefits from having a weak negotiator in power. For example, according to ENSB, governments that were installed or supported by the CIA in 1947-1989 were more likely to divert public expenditure in favor of US products. If the citizens are extremists, however, the US supports the elite for both economic and geopolitical reasons. The thickness of the gray area, which is equal to $\left|\Delta W^{i}\right|+\left|\Delta W^{F}\right|$, measures the probability of US interventions if $\mu$ is distributed uniformly. A look at equations ?? and ?? reveals that a greater geopolitical importance of $H$ makes US interventions more likely if the citizens are extremists.

In this simple model, $E$ never intervenes in equilibrium, since it is prevented to do so by either repression $/ F$ 's interventions, or the surrender of power. However, in circumstances in which repression $/ F$ 's interventions are motivated by the need to stave off an intervention by $E$, one could still say that $H$ is contested between the two foreign countries. From the description of the SPE in the Appendix, it is easy to see that the threat of an intervention by $E$ exists only if ideology is extreme 12 So, while $H$ may be intervened in by $F$ for a range of ideological preferences, it may be contested only in extreme cases. This result suggests that we should observe powerful countries intervene in countries that are economically dependent on them, with relatively little interference from other powerful countries. As I discuss in Section 4, this may help explain why the USA, Britain, France, and the USSR concentrated their interventions in specific spheres of influence during the 20th century.

In the example just described, regime change only leads to a change in alignment to the USSR, and the country is contested between the two superpowers, if the citizens are extremist. However, the history of the Cold War provides many examples of regimes that posed a geopolitical threat to the West, despite the fact that their supporters were not extremist leftists. In an extension included in the working paper version of the paper (Bonfatti 2015), I show that, if rents conceded to $F$ in the past are hard to renegotiate

\footnotetext{
${ }^{12}$ If $\xi \in(\underline{\xi}, \bar{\xi})$, it is $\Delta W^{E}=0$, and $E$ 's equilibrium strategy prescribes $m^{E}=0$ always.
} 
(for example, because this would damage $F$ 's reputation), $i$ may have an incentive to grant unilateral rents to $F$ before regime change may occur. This may happen when $i$ gains more from an agreement than $c$, and can then commit not to renegotiate a high level of rents that $c$ would instead re-negotiate. When $i$ grants such rents, regime change always leads to a change in alignment, since $c$ prefers to sign a suboptimal agreement with $E$, than to ratify high pre-existing rents. What is interesting about this case is that even a moderate $c$ becomes a geopolitical threat to $F$, due to her strong economic nationalism. A greater geopolitical importance of $H$, then, makes not only radical but also moderate political transitions less likely. As I argue in the next section, this result may help explain the negative impact of the Cold War on democratisation in the 1960s and 1970s.

\section{Foreign interventions and regime change in the 20th century.}

I now interpret some of the broad patterns of foreign interventions in the 20th century in light of the model developed in previous sections. In Online Appendix A (available on the author's website), I look at the experience of a few countries in greater detail.

The majority of 20th century interventions were conducted by a handful of countries: the USA, Britain, France, the USSR, and China. A cursory look at these interventions immediately reveals a first pattern: these powerful states did not intervene at random around the world, but tended to focus on specific areas, often called their "spheres of influence." One major exception was that of Cold War interventions, when countries in one bloc often interfered in the sphere of influence of countries in the other bloc. I return to this latter point below.

By and large, developing countries were affiliated to the sphere of influence of their main economic partner. This is particularly evident in the changing affiliation of Latin America, a region with a longer history of foreign interventions than Africa or Asia (excluding colonial interventions). Until the second half of the 19th century, Britain, France and Germany were Latin America's main economic partners, and also the countries that most often sent gunboats to the Latin American shores. However, as Latin America re-oriented its economy towards the US after 1890, it came under increasing US influence. By the end of WWI the US was the most influential country in Central America, and by the end of the 1920s this extended to most of South America as well (Coatsworth 2010, p. 202). Having established Latin America as its sphere of influence, the US became very active in this region. For example, between 1948 and 1990, it "... secured the overthrow of at least twenty-four governments [...], four by direct use of US military force, three by means of CIA-managed revolts or assassination, and seventeen by encouraging local military and political forces to intervene without direct US participation, usually through military coups d'etat" (Ibid., p. 220). The US's priority right of intervention in Latin America became tacitly accepted by other Western powers, although it was challenged by the USSR after 1959 .

As Africa and Asia became independent of colonial control, they soon became affiliated to the spheres of influence of their former colonizers, which were typically also their main economic partners. Just like the US was very active in Latin America, Britain and France 
became very active in their former empires. Between 1959 and 1979, France undertook 18 military interventions in black Africa, to count only the major ones (Luckham 1982, p. 61). France was also by far the largest supplier of weapons to francophone Africa, and maintained a significant military presence in many of its former colonies for decades after independence (Luckham 1982, pp. 57, 62). Similarly, Britain intervened 17 times in 15 former colonies in Africa, the Middle East and Asia in the 1960s, while in the 1970s her military interventions concentrated on Sub-Saharan Africa (van Wingen and Tillema 1980, p. 294; Rouvez 1994, p. 26). At the same time, the other Western powers largely refrained from interfering, unless a co-ordinated action was explicitly requested (Schraeder 2000, pp. 398-399; van Wingen and Tillema 1980, p. 295).13

Most often, foreign interventions were meant to prevent, or reverse, instances of regime change that posed a threat to the dominant power's investments. Early examples of this second pattern are provided by US interventions in Central America. Between 1898 and 1934, the US intervened in Cuba, the Dominican Republic, Haiti, Honduras, Nicaragua and Panama, often leaving a long-standing military presence in the country subject to intervention. These interventions were meant to re-establish domestic political stability, preventing the rise of insurgent movements that put US property at risk (e.g. Thomas 1971, p. 477).

Later examples are Guatemala (1954) and Iran (1953). In Guatemala, the new regime inaugurated by the Arbenz government (1950-1954) launched an ambitious program of economic reforms, which included the expropriation of the vast land holdings of United Fruit, the US company. Within a few years, a CIA-orchestrated coup overthrew Arbenz, bringing the country back to a series of conservative military governments that lasted until the 1990s 14 In Iran, the election of Mossaddeq in 1951 marked a significant change in political regime, leading to greater domestic redistribution and a reduction in the privileges of Anglo-Iranian, the British oil company. In reaction, a British-US supported coup overthrew Mossaddeq in 1953, replacing him with a new government that quickly adopted more conciliatory measures towards Anglo-Iranian.

A similar pattern can be observed in French interventions. Upon obtaining independence, various former French colonies (Central African Republic, Congo, Gabon, Chad, Madagascar and Senegal) gave France privileged access to strategic raw materials. According to Luckham (1982, p. 69), all of France's major interventions in Africa in the 1970s (including the Central African Republic and Chad) took place in situations where regime change represented a threat to the privileges of French investors.

\footnotetext{
${ }^{13}$ The US, Britain, and France were not the only countries to frequently engage in foreign interventions. Belgium was another very interventionist former colonizer, with interventions in the Congo, Rwanda and Burundi. The USSR was also very active, with a special focus on countries of Eastern Europe whose economies were tightly linked to its own. And while China's interventions were more erratic in the 1960s and 1970s - apparently being driven mostly by the desire to favor anti-imperialism - she is currently adopting an assertive role in Africa, a continent that is becoming increasingly connected to the Chinese economy.

${ }^{14}$ The historical literature clearly points to a direct link between the expropriation of US investments and the 1954 coup (e.g. Olson 1979; Cockcroft 1996). In a recent paper, Dube, Kaplan and Naidu (2011) find evidence of this link in the abnormal performance of United Fruit's shares in the days before the coup.
} 
In summary, foreign interventions mattered, and they selectively supported governments who could be trusted to be generous towards foreign investors. But what kind of governments were these? Aidt and Albornoz (2011) emphasize the role of local elite, who owned assets complementary to foreign capital and had thus an interest in being generous towards it. While this mechanism was important in some cases, there is evidence that Western interventions also favored groups with strong trade links with the foreign country, or groups that benefited disproportionately from the foreign country's financial support ${ }^{15}$ For example, in Central America, the US supported an elite of exporters of tropical products, for which the US was the key market. In Sub-Saharan Africa, Britain and France intervened in favor of a bureaucratic and military elite (Berman 1974, p. 8). This derived its income from government revenues that ultimately relied on continued access to foreign markets for key national exports, and on foreign loans and aid. In addition, the African armies were highly dependent on the former colonizers for arms, training, advisers and basic military doctrine, and were, as a consequence, particularly sensitive to external pressure (Berman 1974, p. 7). Online Appendix A provides further examples.

Where foreign investments attracted foreign interventions, they also shaped the domestic politics of regime change. Economic nationalism, or "anti-imperialism" was, in most of these countries, an additional force behind the struggle for regime change. In other words, the opposition did not want to go to power only to implement redistribution, but also to reverse policies deemed too generous towards foreign investments. While this third pattern has been given little attention by the economics literature, it played a crucial role in countries with large stocks of foreign investments (I consider the cases of Cuba, Chile and Venezuela in Online Appendix A).

The analysis conducted in Section 3 suggests one way to explain these patterns from economic fundamentals. The US, Britain and France, were each the main trade partner - and main source of financial support - of a group of developing countries. Proposition 1, then, suggests why these developing countries became divided into spheres of influence: their economic links to the established power were simply too strong, for an external power to be able to compete. Within their spheres of influence, the Western countries could extract rents for their investors, but the more so, the weaker was their counterpart in negotiations. This naturally induced them to support governments with direct links to their trade or financial support. Opposite calculations motivated economic nationalism, which pushed against these governments. Proposition 1 explains the importance of economic nationalism with the fact that developing countries were very dependent on economic agreements with the established power (high $\gamma$ ), and gains from an agreement unequally distributed (high $\theta_{i}$ and $\theta_{c}$ ). Literally, the proposition suggests that economic nationalism should have facilitated regime change: this may fit the case of Venezuela, a country where economic nationalism was a driving force behind the transition to democracy in the 1960s and 1970s (see Online Appendix A).

\footnotetext{
${ }^{15}$ Complementarity between local and foreign capital is also less likely to be important in countries where foreign investments are located in secluded enclaves (e.g. capital-intensive mines), their main link with the rest of the economy being through taxation.
} 
The extension outlined at the end of Section 3 provides some further insights. In an environment such as that of the early 20th century, where the West had lucrative investments in many developing countries, it might be hard for the Western governments to accept expropriation in one country, lest the other would follow suit. The incumbent elites would then have an incentive to concede even larger rents, to further differentiate themselves from the more economically nationalist opposition groups. In these cases, economic nationalism might represent not only an economic threat, but also a threat to the logic of the spheres of influence. This mechanism must have played a particularly important role during the Cold War, when geopolitical competition intensified. However in this period, ideological preferences were also important. To these issues I now turn.

\subsection{The Cold War.}

During the Cold War, the groups that the West sought to exclude from power began to receive the support of the USSR and its allies. This led to an escalation of the domestic conflict, which in some extreme cases (such as Vietnam) degenerated into proxy wars between the two superpowers. With insight, this is probably what Kwame Nkrumah - the first prime minister of independent Ghana - was hoping to avoid when, addressing the UN General Assembly in 1958, he urged the newly-independent African countries to remain non-aligned in the Cold War (Latham 2010, p. 258).

Cold War competition for the alignment of developing countries peaked in the 1960s and 1970s, largely due to evolutions in Soviet foreign policy ${ }^{16}$ It was in this phase that the USSR began to intervene in Latin America, Asia and Africa, with a view to install friendly groups in power and thus create international support for its broader Cold War goals. The impact of this escalation on regime change is particularly evident in the case of Latin America, a region with a long history of foreign interventions, but where democratization was well underway in the 1950s ${ }^{18}$ From 1959 onwards, the USSR supported the Cuban revolution, leading to one of the most serious violation of the logic of the spheres of influence in the 20th century. This was a turning point. In subsequent years, the urge to avoid a "second Cuba" led to a scaling up of US interventions in support of the ruling elite, and against the ongoing political transition. Since the transition was taking the form of democratization, the effect

\footnotetext{
${ }^{16}$ During Stalin's rule, the USSR's central concern was "to keep and to digest its principal war gains - control over Eastern Europe - while avoiding a premature collision with the ascending Western power, America" (Brzezinski 1992, p. 35) ${ }^{17}$ Soviet foreign policy took a new turn only with Khrushchev's accession to power (1958). In this year, a distinctively new phase started, one in which, for the Soviets, "Eurasia was still the central stake but no longer the central front", "containment was to be defeated by encirclement" (Ibid. 1992, p. 38). This phase lasted roughly until the end of the 1970s, when the looming crisis of the Soviet economy and the disastrous invasion of Afghanistan (1979) induced the Soviet leadership to pursue a less aggressive foreign policy.

${ }^{18}$ Throughout the first half of the century, a landed and commercial elite had retained power in Latin America, sometimes with the help of US interventions. However from the 1920s onwards, a large number of reformist parties were formed (see Angell 1994), most of which were committed to gaining power by means of fair elections. These parties came to power in Guatemala (1945), Venezuela (1944), Costa Rica (1948), Bolivia (1952), and elsewhere. Because of this, the 1950s were perceived as a period of political transition in Latin America.
} 
of the Cold War was to bias US foreign policy against democracy in the 1960s and 1970s. Many US interventions of this period were aimed at removing democratically elected leaders (such as Chile's Allende in 1973), or at supporting undemocratic ones. While the USSR also scaled up the resources available to the opposition, the superior resources committed by the US to the defense of its "own" hemisphere implied that the democratization process came to a halt.

This pattern is illustrated in Figure 3, which plots the average Polity IV democracy score of the Southern and Central American countries (measured on the left) together with ENSB's measure of the number of American countries intervened in by the CIA in each year (measured on the right). ${ }^{19}$ There was a clear upward trend in the quality of democracy in the 1950s, but this suffered a sharp reversal in the 1960s and 1970s, at the same time as a sharp increase in the number of CIA interventions. In the 1980s, the number of CIA interventions dropped, and the quality of democracy began to improve again. This pattern is consistent with ESB's finding that CIA interventions were detrimental to democracy, but it also illustrates how the timing of interventions depended on the intensity of Cold War competition.

Figure 3 ideally here.

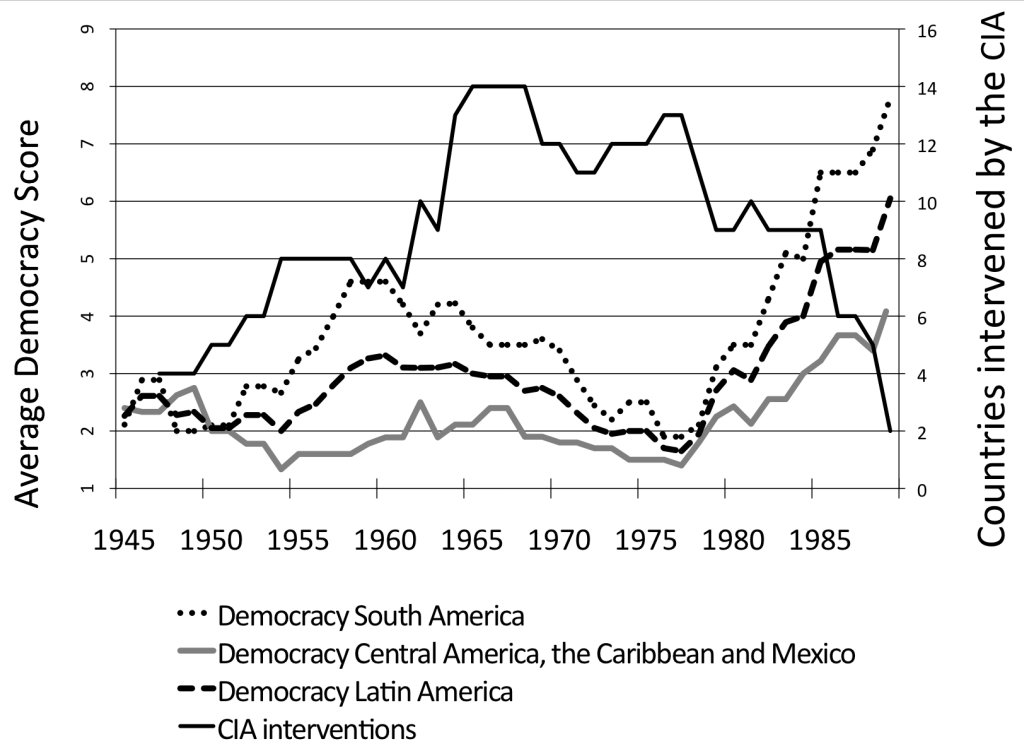

FIGURE 3 CIA interventions and democracy in Latin America, 1945-1989. Sources: Polity IV (democracy), ENSB (CIA interventions)

Despite Nkrumah's pleas, the Cold War had a similar escalating effect in Africa and Asia. There, the USSR fuelled the opposition to regimes that were friendly to former

\footnotetext{
${ }^{19}$ This is the number of American countries where, in a given year, the CIA either installed or supported a government leader. A similarly sharp increase in CIA interventions is evident if we use ENSB's narrow measure of covert CIA interventions; see ENSB's for more details.
} 
colonizers, or supported regimes that antagonized the former colonizers. Among the latter are Ethiopia (1974), Angola (1975), Mozambique (1975), Vietnam (1976) and Iran (1979). It was mainly because of the geopolitical aspects of regime change that the US intervened alongside Britain and France in their spheres of influence in Africa during the Cold War (see, for example, Shraeder 2000) 20

Why did intensification of the Cold War lead the West to more firmly oppose the political transition in developing countries, and thus democracy? The analysis conducted in previous sections provides two possible answers. Suppose we can capture the escalation of the 1960s and 1970s with a scaling up of $\gamma^{F}$ and $\gamma^{E}$. Then, maybe, the groups who would benefit from the political transition were, by and large, extremist communists $(\xi \geq \bar{\xi})$, who could not be trusted to align themselves with the West. Indeed, quite a few of the countries where regime change took place - such as Cuba, Chile and Nicaragua - turned to the Soviets for economic assistance. According to Proposition 1, then, the Cold War should precisely lead to more frequent interventions by the West, and to a lower probability of regime change.

While this explanation may be valid for a number of countries, it may not be the whole story. For one thing, not many opposition groups had a clear communist ideology: in terms of the model, $\xi$ was low. Of course the West liked to portray the regimes they opposed as communist. But so little motivated appear some of these claims (as in the case of the Dominican Republic) ${ }^{21}$ to induce historians and political scientists to conclude that US policy-makers acted irrationally, or "suffered from a kind of anti-Communist malaise or imperial hubris" (Latham 2010, p. 221). Even among governments who did receive Soviet assistance, "While many [...] embraced radical economic policies, the vast majority of them were not Marxist states. Many of them also declared their firm commitment to policies of non-alignment and even suppressed local Communist parties" (Latham 2010, p. 265). This was true in Castro's Cuba and Nasser's Egypt:22 in Allende's Chile, the government leaders were indeed communist, but could hold on to power only with the support of noncommunist allies. In fact, so often did the USSR accept non-communist allies, that the Soviet leadership came under criticism for this at home. ${ }^{23}$

That ideology can fully explain the pattern of Cold War interventions seems particularly hard to believe, given the importance of the West as an economic partner for many developing countries, and the superior resource that the West devoted to the defence of its own spheres of influence. For example, Coatsworth (2010, p. 201) argues that "In its prosecution of the Cold War in the Third World, the United States enjoyed formidable advantages

\footnotetext{
${ }^{20}$ One difference between Latin America and Africa was that, whereas in the former the Iron Curtain fell mostly along the divide between traditional elites and masses, in Africa it also fell along ethnic and other historical divides.

${ }^{21}$ In 1965, the Johnson administration invaded the Dominican Republic to remove Juan Bosch, a democratically elected leader. Although the evidence of Communist activity among the pro-Bosh forces was very thin, Johnson concluded that the risk of subversion was simply intolerable (Latham 2010, p. 271).

${ }^{22}$ The latter fought Communism at home, and even spread an anti-Communist campaign into Syria and Iraq, accusing the Soviets of hindering the cause of Arab unity and interfering in internal Arab affairs.

${ }^{23}$ That was the accusation levelled at Kruschev in the 1960s. According to Latham (2010), China's Cold War interventions showed an even stronger degree of ideological flexibility, putting great emphasis on anti-imperialism.
} 
over its Soviet rival. Economic strength gave US leaders a decided financial and material advantage over the Soviets." Indeed, the US embargo on Cuba (1962-) inflicted large and long-standing costs on the Cuban economy, despite Soviet assistance. This stands in sharp contrast with the experience of the progressive governments who managed to remain in good terms with the US, and received massive amounts of aid in return ${ }^{24}$ In summary, while a strong pro-Soviet ideology was not frequent, the economic incentives to remain with the West were clear and strong: in terms of the model, $\bar{\xi}$ was high, because both $\gamma$ and $\gamma^{F}$ and $\gamma^{E}$ were high.

The extension outlined at the of Section 3 provides an alternative interpretation. If Western rents, once established, were hard to renegotiate, the elite had an incentive to grant even more of them, and even a non-communist opposition could become a geopolitical threat. That was because of economic nationalism: the opposition really wanted to expropriate Western rents, and, in the face of Western intransigence, were willing to turn to the USSR to reach that goal.

Consistently with this alternative interpretation, many of the governments that turned to the USSR or China for economic assistance seem to have been motivated more by the desire to eliminate the West's domination of their economy, than by their communist ideology. This was the case of the Castro government, but economic nationalism can also explain why Allende was able to secure enough domestic support (see Online Appendix A). There is clear evidence that, for these and other governments, the issue of foreign investments was a stumbling block in the way of friendly relations with the West. There is also evidence that reputation concerns played a role: sometimes, Western strategists would have liked to accommodate on the expropriation of foreign investments, but had their hands tied by the reputation concerns of domestic lobbies ${ }^{25}$ Finally, there is evidence that, in the 1950s and 1960s, the elite-led governments continued to grant very generous terms to Western investors, adding up to the large rents inherited from the pre-Cold War period. The extension outlined at the of Section 3 suggests why this was a rational self-preservation strategy, despite the fact that it fuelled economic nationalism at home.

In both interpretations, the model suggests that a scaling up of $\gamma^{F}$ and $\gamma^{E}$ should result in a lower probability of regime change, and, for some distribution of $\mu$, an increased frequency of Western interventions. These predictions fit the pattern of Figure 3 well.

As the Cold War drew to a close in the 1980s, developing countries lost much of their geopolitical importance. As illustrated in Figure 3, this resulted in a sharp drop of US interventions in Latin America. At the same time, the democratization process that had

\footnotetext{
${ }^{24}$ For example, the Frei government in Chile and the Betacourt governments in Venezuela. For more details on US aid to Latin America in the 1960s, see Taffet (2007).

${ }^{25} \mathrm{An}$ example of this is the famous Hickenlooper Amendment, a law passed in 1962 with which Congress made it mandatory for the President to cut aid to countries that expropriated American companies. The Amendment was intended to establish a reputation of intransigence towards renegotiation, and was precisely pushed through by Congress to prevent the President from sacrificing the interests of US investors to broader geopolitical calculations. In fact, according to Vandevelde (1988), electoral incentives make Congress particularly keen on imposing sanctions against the expropriation of US companies, whereas the President may be more concerned with the foreign policy consequences of sanctions.
} 
been interrupted in the early 1960s resumed in the 1980s. In Africa, it resumed in the early 1990s. The transition to democracy was largely supported by the West, who proved able to entertain good economic relations with whoever went to power. In terms of the model, $\gamma^{F}$ and $\gamma^{E}$ went back to a low value in the 1980s. This resulted in a lower geopolitical cost of international disruption. At the same time, it resulted in a lower probability that $c$ 's economic nationalism would lead to international disruption, since $c$ 's outside option had became less attractive. Both factors reduced the willingness of the West to intervene in support of the status quo, forcing the elite to make concessions. As put by Coatsworth (2010), after the end of the Cold War, contenders were simply compelled to negotiate peace in the context of Western hegemony.

\section{Conclusion.}

I have constructed an economic theory of foreign interventions and regime change, which may help explain several patterns of Western interventions in the 20th century. My results may help explain why the Cold War had such a radicalising effect on foreign interventions and regime change in the 1960s and 1970s, even in countries for which the West was a key economic partner and where the opposition did not have a strong communist ideology. More in general, they may help interpret how the West's preference for democracy is determined by its economic links with the country in question, and by the current level of geopolitical competition.

I conclude by discussing two possible extensions. First, suppose that the ruling elite has an option to undertake reforms that would help the economy grow (for example, by creating good economic institutions). Acemoglu and Robinson (2012) suggest that the elite is unlikely to do so, since economic success would put external groups in a position to threaten the elite's supremacy. In the context of my model, there would be an additional reason why this would be true: by creating more links between the masses and the international economy, the reforms could weaken the special position of the elite in $F$ 's preferences. Notice that this effect of reforms would be positive for $F$, since it would reduce the risks associated with regime change. This may explain why, in the 1950s and 1960s, US aid was primarily aimed at promoting modernization, which was seen as a way to prevent the inroad of communism (Latham 2010). The diverging incentives of the elite and $F$ suggest that there may be more to learn about the efficacy of development aid when donor countries may also be involved in regime change ${ }^{26}$

A second, somewhat symmetric extension would be to consider the case of nationalistic new democracies ${ }^{27}$ A new democracy representing less outward-oriented masses may want to reduce the influence of domestic groups with strong economic links with a powerful foreign country. This may involve the adoption of inefficient "closeness" policies, or forced

\footnotetext{
${ }^{26}$ For example, US aid entirely missed its modernization goals in the 1950s and 1960s. At least in part, this was because the elite blocked US-sponsored development, while red-baiting the opposition and diverting US aid to the fighting of communism. Because of this failure, in the 1970s US aid became much more oriented towards supporting friendly regimes (Latham 2010).

${ }^{27}$ I thank an anonymous referee for suggesting this extension.
} 
diversification in favor of other countries. For example, this seems to be the current strategy of some Latin American countries (Bolivia, Ecuador and Venezuela), which are quite inimical to the US and its allies, but quite keen on diversifying towards China or Iran. The governments of these countries are also deeply suspicious towards other leftist governments that are successfully pursuing a modernization strategy, such as Brazil or Chile (Russell 2011). Little is known about what determines the choice between these two paths, and how each country's history of foreign interventions may be relevant. I believe this may be an important area for future research.

\section{References.}

Acemoglu, D., and J. Robinson (2006). Economic Origins of Dictatorship and Democracy, Cambridge (MA), Cambridge University Press

- (2012). Why Nations Fail - The Origin of Power, Prosperity and Poverty, London, Profile Books

Aidt, T., and F. Albornoz (2011). "An economic theory of political institutions: foreign intervention and overseas investments", Journal of Development Economics, V. 94, pp. $192-201$

Aidt, T., F. Albornoz and M. Gassebner (2012). "The Golden Hallo and Political Transitions", in CESIfo Working Papers, N. 3957

Aidt, T., and U. Hwang (2008). "One Cheer for Foreign Lobbying", Cambridge Working Papers in Economics, N. 860

Antras, P., and G. Padro-i-Miquel (2011). "Foreign Influence and Welfare" Journal of International Economics, V. 84, N. 2, pp. 135-48

Berman, B.J. (1974). "Clientelism and Neo-colonialism: Center-Periphery Relations and Political Development in African States", Studies in Comparative International Development, V. 9, N. 2, p. 3

Besley, T., and T. Persson (2011). "The Logic of Political Violence", Quarterly Journal of Economics, forthcoming

Binmore, K., A. Rubinstein and A. Wolinsky (1986). "The Nash Bargaining Solution in Economic Modelling", The Rand Journal of Economics, V. 17, N. 2, pp. 176-88

Bonfatti, R. (2015). "An Economic Theory of Foreign Interventions and Regime Change", GEP Working Paper Series, University of Nottingham

Brzezinski, Z. (1992). "The Cold War and its Aftermath", Foreign Affairs, V. 71, N. 4, pp. 31-49

Coatsworth, J.H. (2010). "The Cold War in Central America, 1975-1991", in Cambridge History of the Cold War, Cambridge, CUP

Cockcroft, J D. (1996). Latin America: History, Politics and US Policy, Chicago, NelsonHall Publishers

Dube, A., E. Kaplan and S. Naidu (2011). "Coups, corporations, and classied information", Quarterly Journal of Economics, forthcoming

Easterly, E., S. Satyanath and D. Berger (2008). "Superpower interventions and their 
consequences for democracy: An empirical inquiry". NBER Working Papers, N.13992

Easterly, W., D. Nunn, S. Satyanath and Daniel Berger (2010). "Commercial Imperialism? Political Influence and Trade During the Cold War", mimeo, Harvard University

Endoh, M. (2005). "Cross-Border Political Donations and Pareto- Effcient Tariffs" in Discussion Papers, No . 915, Yale Economic Growth Center

Head, K., T. Mayer and J. Ries (2010). "The Erosion of Colonial Linkages after Independence", Journal of International Economics, Volume 81, N. 1, pp. 1-14

Kuziemko, I., and E. Werker. (2006). "How Much is a Seat on the Security Council Worth? Foreign Aid and Bribery at the United Nations" Journal of Political Economy, V. 114, N. 5

Lizzeri, A., and N. Persico (2004). "Why Did the Elites Extend the Suffrage? Democracy and the Scope of Government, With an Application to Britains Age of Reform", in Quarterly Journal of Economics, V. 119, N. 2, pp. 707-65

Luckham, R. (1982). "French Militarism in Africa", Journal of African Political Economy, N. 24, pp. 55-84

Mitchell, B.R. (1998). International Historical Statistics the Americas, 1750-1993, Basingstoke (UK), MacMillan Reference

Mothoo, A. (1999). Bargaining Theory with Applications, Cambridge (UK), Cambridge University Press

Nash, J. (1950). "The Bargaining Problem", Econometrica, N. 18, pp. 155-62

Olson, G. (1978). "US Foreign Policy and the Third World Peasant: Land Reform in Asia and Latin America", New York, Praeger Publishers

Padro-i-Miquel, G. (2007). "The Control of Politicians in Divided Societies: The Politics of Fear" in Review of Economic Studies, V. 74, N. 4, pp. 1259-74

Schraeder, P.J. (2000). "Cold War to Cold Peace: Explaining US-French Competition in Francophone Africa", Political Science Quarterly, V. 115, N. 3

Taffet, Jeffrey (2007). Foreign Aid and Foreign Policy: the Alliance for Progress in Latin America, New York, Routledge

Ticchi, D., and Andrea V. (2008). "War and Endogenous Democracy", IZA Discussion Papers, N. 3397, March 2008

Thomas, H. (1971). Cuba, or the Pursuit of Freedom, London, Eyre and Spottiswoode UN (1955). Foreign Capital in Latin America, New York, 1955

van Wingen, J., and H. K. Tillema (1980). "British Military Intervention After World War II: Militance in a Second-Rank Power", Journal of Peace Research, V. 17, N. 4, pp. 291-303

Vandevelde, K. (1988). "Reassessing the Hickenlooper Amendment", Virginia Journal of International Law, N. 115

\section{Appendix.}

6.1. Full description of the SPE.

Proposition A1 describes the SPE of the overall game. For the SPE of the subgame that 
starts after $i$ has not surrendered power, drop the first three lines (until "... phase of stage $4 ")$.

Because I do not commit to specific tie-breaking rules in stages 2 and 3, players have best-response correspondences rather than functions. However, I find that, for some of the histories that put them at a tie, players have a unique best response that is consistent with the strategies of players who move at an earlier stage being well-defined. Because all strategies must be well defined at a SPE, strategies must feature such best-response at a SPE.

Let $R$ be an indicator function for $c$ staging a revolution. Then:

Proposition A1. In a pure strategy SPE, in $t=1, i$ surrenders power if $\mu \leq \Delta W$, does not surrender power otherwise. If $i$ surrenders power, the game moves directly to the bargaining phase of stage 4. If $i$ does not surrender power, if $\xi \geq \frac{1-\theta_{i}-\theta_{c}}{2} \gamma$ (so that $\left.\Delta W^{F} \leq 0, \Delta W^{E} \geq 0\right)$ :

$t=2 . i: i$ sets $m=\Delta W^{c, F, E}-\mu$ if $\mu \in\left(\Delta W, \Delta W^{c, F, E}\right], m=0$ if $\mu \notin\left[\Delta W, \Delta W^{c, F, E}\right]$. If $\mu=\Delta W$, may set $m=0$ or $m=-\Delta W^{i}$.

$t=2 . i i: F$ sets $m^{F}=\Delta W^{c, E}-m-\mu$ if $\mu \in\left(\Delta W^{c, F, E}-m, \Delta W^{c, E}-m\right], m^{F}=0$ if $\mu \notin\left[\Delta W^{c, F, E}-m, \Delta W^{c, E}-m\right]$. Suppose $\mu=\Delta W^{c, F, E}-m$. If $m \in\left[0,-\Delta W^{i}\right), F$ sets $m^{F}=-\Delta W^{F}$; for any other history, may set $m^{F}=0$ or $m^{F}=-\Delta W^{F}$.

$t=2 . i i i: E$ sets $m^{E}=\Delta W^{c}-m-m^{F}-\mu$ if $\mu \in\left[\Delta W^{c}-m-m^{F}, \Delta W^{c, E}-m-m^{F}\right)$, $m^{E}=0$ if $\mu \notin\left[\Delta W^{c}-m-m^{F}, \Delta W^{c, E}-m-m^{F}\right]$. Suppose $\mu=\Delta W^{c, E}-m-m^{F}$. If $m^{F} \in\left[0,-\Delta W^{F}\right)$, or if $m^{F}=-\Delta W^{F}$ and $m \in\left[0,-\Delta W^{i}\right)$, E sets $m^{E}=0$; for any other history, may set $m^{E}=0$ or $m^{E}=-\Delta W^{E}$.

$t=3:$ c sets $R=1$ if $\mu<\Delta W^{c}-m-m^{F}-m^{E}, R=0$ if $\mu>\Delta W^{c}-m-m^{F}-m^{E}$. Suppose $\mu=\Delta W^{c}-m-m^{F}-m^{E}$. If $\Delta W^{E}>0$, and $m^{E} \in\left(-\Delta W^{E}, 0\right]$, c sets $R=1$; if $\Delta W^{E}=0$, and either $m^{F} \in\left[0,-\Delta W^{F}\right)$, or $m^{F}=-\Delta W^{F}$ and $m \in\left[0,-\Delta W^{i}\right)$, she sets $R=0$; for any other history, may set $R=1$ or $R=0$.

and the game then moves to the bargaining phase of stage 4. If $\xi<\frac{1-\theta_{i}-\theta_{c}}{2} \gamma$ (so that $\left.\Delta W^{F}>0, \Delta W^{E} \leq 0\right)$, instead:

$t=2 . i: i$ sets $m=\Delta W^{c, F, E}-\mu$ if $\mu \in\left(\Delta W, \Delta W^{c, F, E}\right]$, sets $m=0$ if $\mu \notin\left[\Delta W, \Delta W^{c, F, E}\right]$. If $\mu=\Delta W$, may set $m=0$ or $m=-\Delta W^{i}$.

$t=2 . i i: F$ sets $m^{F}=\Delta W^{c, E}-m-\mu$ if $\mu \in\left[\Delta W^{c, E}-m, \Delta W^{c, F, E}-m\right)$, sets $m^{F}=0$ if $\mu \notin\left[\Delta W^{c, E}-m, \Delta W^{c, F, E}-m\right]$. Suppose $\mu=\Delta W^{c, F, E}-m$. If $m \in\left[0,-\Delta W^{i}\right), F$ sets $m^{F}=0$; for any other history, may set $m^{F}=0$ or $m^{F}=-\Delta W^{F}$.

$t=2 . i i i: E$ sets $m^{E}=\Delta W^{c}-m-m^{F}-\mu$ if $\mu \in\left(\Delta W^{c, E}-m-m^{F}, \Delta W^{c}-m-m^{F}\right]$, $m^{E}=0$ if $\mu \notin\left[\Delta W^{c, E}-m-m^{F}, \Delta W^{c}-m-m^{F}\right]$. Suppose $\mu=\Delta W^{c, E}-m-m^{F}$. If $m^{F} \in\left(-\Delta W^{F}, 0\right], E$ sets $m^{E}=0$; for any other history, may set $m^{E}=0$ or $m^{E}=-\Delta W^{E}$. 
$t=3: c$ sets $R=1$ if $\mu<\Delta W^{c}-m-m^{F}-m^{E}, R=0$ if $\mu>\Delta W^{c}-m-m^{F}-m^{E}$. Suppose $\mu=\Delta W^{c}-m-m^{F}-m^{E}$. If $\Delta W^{E}<0$ and $m^{E} \in\left[0,-\Delta W^{E}\right)$, c sets $R=0$; if $\Delta W^{E}=0$ and $m^{F} \in\left(-\Delta W^{F}, 0\right]$, she sets $R=1$; for any other history, may set $R=1$ or $R=0$.

and the game then moves to the bargaining phase of stage 4.

Proof. I begin by looking at the SPE of the subgame that starts after $i$ has not surrender power. Suppose $\xi \geq \frac{1-\theta_{i}-\theta_{c}}{2} \gamma$. It is one of the following: $\Delta W^{F}=\Delta W^{E}=0$ (if $\xi=$ $\frac{1-\theta_{i}-\theta_{c}}{2} \gamma$ ); $\Delta W^{F}<0, \Delta W^{E}=0$ (if $\xi \in\left(\frac{1-\theta_{i}-\theta_{c}}{2} \gamma, \bar{\xi}\right)$ ); or $\Delta W^{F}<0, \Delta W^{E}>0$ (if $\xi \geq \bar{\xi})$. Solve backward. Stage 3. If $\mu<\Delta W^{c}-m-m^{F}-m^{E}$, c's unique optimal

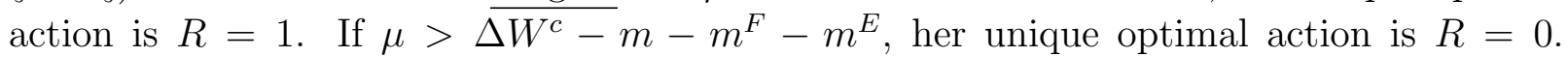
If $\mu=\Delta W^{c}-m-m^{F}-m^{E}$, both $R=0$ and $R=1$ are optimal actions. But if $\Delta W^{E}>0$, and $m^{E} \in\left(-\Delta W^{E}, 0\right], R=0$ cannot be part of an equilibrium strategy, since $E$ 's optimal strategy would then not be well defined ${ }^{28}$ Similarly, if $\Delta W^{E}=0$, and either $m^{F} \in\left[0,-\Delta W^{F}\right)$, or $m^{F}=-\Delta W^{F}$ and $m \in\left[0,-\Delta W^{i}\right), R=1$ cannot be part of an equilibrium strategy, since the optimal strategy of $F$ (in the first case) or $i$ (in the second case) would then not be well defined ${ }^{29}$ Stage 2.iii. If $\Delta W^{E}=0$, E's optimal strategy must prescribe $m^{E}=0$ always. Indeed, this is what the strategy in the proposition prescribes. If $\Delta W^{E}>0$, if $\mu<\Delta W^{c}-m-m^{F}$, E's unique optimal action is $m^{E}=0$ (enough to have $R=1$ ). If $\mu \in\left[\Delta W^{c}-m-m^{F}, \Delta W^{c, E}-m-m^{F}\right.$ ), E's unique optimal action is $m^{E}=\Delta W^{c}-m-m^{F}-\mu$ : it is the cheapest way to trigger $R=1$, and yields $\Delta W^{E}-\left|m^{E}\right|>0$. If $\mu=\Delta W^{c, E}-m-m^{F}$, depending on $c^{\prime}$ 's tie-breaking rule, $E$ may or may not be at at tie. If $c^{\prime}$ 's tie-breaking rule when $m^{E}=-\Delta W^{E}$ is $R=0, E$ is not at a tie, and her unique optimal action is $m^{E}=0$; if $c^{\prime}$ 's rule is $R=1, E$ is at a tie, and both

\footnotetext{
${ }^{28}$ Suppose $c$ 's strategy prescribed $R=0$ given this history. One step back, if $\mu \in$ $\left[\Delta W^{c}-m-m^{F}, \Delta W^{c, E}-m-m^{F}\right), E$ 's optimal action would be $m^{E}=\Delta W^{c}-m-m^{F}-\mu-\epsilon$, with $\epsilon>0$ infinitesimally small (it is the cheapest way to obtain $R=1$, and one that yields $\Delta W^{E}-\left|m^{E}\right|>0$ ). $E$ 's optimal strategy would then not be well defined.

${ }^{29}$ In both cases, $\Delta W^{E}=0$ implies that $E$ 's strategy must prescribe $m^{E}=0$ always. The first history implies $\Delta W^{F}<0$. Suppose $c^{\prime}$ 's strategy prescribed $R=1$ given the first history. Two steps back, if $\mu \in\left(\Delta W^{c, F}-m, \Delta W^{c}-m\right]$, F's optimal action would be $m^{F}=\Delta W^{c}-m-\mu+\epsilon$, with $\epsilon>0$ infinitesimally small (it is the cheapest way to obtain $R=0$, and one that yields $-\Delta W^{F}-m^{F}>0$ ). $F$ 's optimal strategy would then not be well defined. Suppose $c$ 's strategy prescribed $R=1$ given the second history. There are two cases, $\Delta W^{F}=0$ and $\Delta W^{F}<0$. If $\Delta W^{F}=0, F^{\prime}$ 's strategy must prescribe $m^{F}=0=-\Delta W^{F}$ always. Three steps back, if $\mu \in\left(\Delta W^{c, i}, \Delta W^{c}\right]$, i's optimal action would be $m=-\Delta W^{c}-\mu+\epsilon$, with $\epsilon>0$ infinitesimally small (it is the cheapest way to obtain $R=0$, and one that yields $-\Delta W^{i}-m>0$ ). $i$ 's optimal strategy would then not be well defined. Suppose $\Delta W^{F}<0$. Since $c$ 's strategy prescribes $R=1$ given the second history, two steps back, $F$ 's optimal strategy must prescribe $m^{F}=0$ when $\mu=\Delta W^{c, F}-m$ and $m \in\left[0,-\Delta W^{i}\right.$ ) (since even $m^{F}=-\Delta W^{F}$ would only lead to $R=1$ ). In addition, in light of the fact that $c$ 's strategy must prescribe $R=0$ given the first history, $F^{\prime}$ 's strategy must prescribe $m^{F}=\Delta W^{c}-m-\mu$ if $\mu \in\left(\Delta W^{c, F}-m, \Delta W^{c}-m\right]$ (it is the cheapest way to trigger $m^{E}=0$ and thus $R=0$, and one that yields $\left.-\Delta W^{F}-m^{F}>0\right)$. It follows that, three steps back, if $\mu \in\left(\Delta W^{i, c, F}, \Delta W^{c, F}\right]$, $i$ 's optimal action would be $m=\Delta W^{c, F}-\mu+\epsilon$, with $\epsilon>0$ infinitesimally small (it is the cheapest way to trigger $m^{F}=\Delta W^{c}-m-\mu$ and thus $R=0$, and one that yields $-\Delta W^{i}-m>0$ ). $i$ 's optimal strategy would then not be well defined.
} 
$m^{E}=0$ (leading to $R=0$ ) and $m^{E}=-\Delta W^{E}$ (leading to $R=1$ ) are optimal actions. But if $m^{F} \in\left[0,-\Delta W^{F}\right)$, or if $m^{F}=-\Delta W^{F}$ and $m \in\left[0,-\Delta W^{i}\right), m^{E}=-\Delta W^{E}$ cannot be part of an equilibrium strategy, since the optimal strategy of $F$ (in the first case) or $i$ (in the second case) would not be well defined. ${ }^{30}$ If $\mu>\Delta W^{c, E}-m-m^{F}$, E's unique optimal action is $m^{E}=0$ ( since to have $R=1$ would cost more than $\Delta W^{E}$ ). Stage 2.ii. If $\Delta W^{F}=0, F^{\prime}$ 's optimal strategy must prescribe $m^{F}=0$ always. Indeed, this is what the strategy in the proposition prescribes. If $\Delta W^{F}<0$, if $\mu>\Delta W^{c, E}-m, F^{\prime}$ 's unique optimal action is $m^{F}=0$ (enough to have $m^{E}=0$ and $R=0$ ). If $\mu \in\left(\Delta W^{c, F, E}-m, \Delta W^{c, E}-m\right.$ ], $F$ 's unique optimal action is $m^{F}=\Delta W^{c, E}-m-\mu$ : it is the cheapest way to trigger $m^{E}=0$ and thus $R=0$, and yields $-\Delta W^{F}-m^{F}>0$. Next, suppose $\mu=\Delta W^{c, F, E}-m$. Depending on $c$ 's and $E$ 's tie-breaking rules, $F$ may or may not be at a tie. If $c$ 's tie-breaking rule given $m^{F}=-\Delta W^{F}$ and $m^{E}=-\Delta W^{E}$ is $R=1$, and, at the same time, $E$ 's tie-breaking rule given $m^{F}=-\Delta W^{F}$ is $m^{E}=-\Delta W^{E}$, then $F$ is not at a tie, and its unique optimal action is $m^{F}=0$. Notice that this condition does not hold if $m \in\left[0,-\Delta W^{i}\right)$, since the tiebreaking rules of either $E$ or $c$ are required to be different. If the condition does not hold, $F$ is at a tie, and both $m^{F}=0$ (leading to $R=1$ ) or $m^{F}=-\Delta W^{F}$ (leading to $R=0$ ) are optimal actions. But if $m \in\left[0,-\Delta W^{i}\right), m^{F}=0$ cannot be part of an equilibrium strategy, since $i$ 's strategy would then not be well defined ${ }^{31}$ If $\mu<\Delta W^{c, F, E}-m, F^{\prime}$ 's unique optimal strategy is $m^{F}=0$ (since to have $R=0$ would cost more than $-\Delta W^{F}$ ). Stage 2.i. If $\mu>\Delta W^{c, F, E}$, $i$ 's unique optimal action is $m=0$ (enough to have $m^{E}$ and

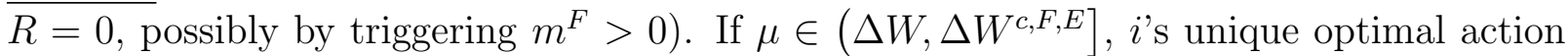
is $m=\Delta W^{c, F, E}-\mu$ : it is the cheapest way to trigger $m^{F}=-\Delta W^{F}$ and thus $m^{E}=0$ and $R=0$, and yields $-\Delta W^{i}-m>0$. Next, suppose $\mu=\Delta W$. Depending on c's and $E$ 's and F's tie-breaking rules, $i$ may or may not be at a tie. If $\Delta W^{F}<0$, and $F^{\prime}$ 's strategy prescribes $m^{F}=0$ when $\mu=\Delta W^{c, F, E}-m$ and $m=-\Delta W^{i}$ (either because the tie-breaking rules of $c$ and $E$ make this $F$ 's optimal action, or because $F$ 's own tie-breaking rule prescribes this), or if $\Delta W^{F}=0$, and $c^{\prime}$ 's tie-breaking rule is $R=1$ when $m=-\Delta W^{i}$, then $i$ is not at a tie, and her unique optimal action is $m=0$. Otherwise, $i$ is at a tie, and

\footnotetext{
${ }^{30}$ Suppose E's strategy prescribed $m^{E}=-\Delta W^{E}$ given the first history. One step back, if $\mu \in$ $\left(\Delta W^{c, F, E}-m, \Delta W^{c, E}-m\right], F$ 's optimal action would be $m^{F}=\Delta W^{c, E}-m-\mu+\epsilon$, with $\epsilon>0$ infinitesimally small (it is the cheapest way to trigger $m^{E}=0$ and thus $R=0$, and one that yields $\left.-\Delta W^{F}-m^{F}>0\right)$. F's optimal strategy would then not be well defined. Suppose E's strategy prescribed $m^{E}=-\Delta W^{E}$ given the second history. One step back, $F$ 's optimal strategy would have to prescribe $m^{F}=0$ when $\mu=\Delta W^{c, E, F}-m$ and $m \in\left[0,-\Delta W^{i}\right.$ ) (since even $m^{F}=-\Delta W^{F}$ would only lead to $m^{E}=-\Delta W^{E}$ and $\left.R=1\right)$. At the same time, in light of the fact that $E$ 's strategy must prescribe $m^{E}=0$ given the first history, $F$ 's strategy must prescribe $m^{F}=\Delta W^{c, E}-m-\mu$ if $\mu \in\left(\Delta W^{c, F, E}-m, \Delta W^{c, E}-m\right]$ (it is the cheapest way to trigger $m^{E}=0$ and thus $R=0$, and one that yields $-\Delta W^{F}-m^{F}>0$ ). It follows that, two steps back, if $\mu \in\left(\Delta W, \Delta W^{c, F, E}\right]$, i's optimal action would be $m=\Delta W^{c, F, E}-\mu+\epsilon$, with $\epsilon>0$ infinitesimally small (it is the cheapest way to trigger $m^{F}=\Delta W^{c, E}-m-\mu$, and thus $m^{E}=0$ and $R=0$, and one that yields $\left.\Delta W^{i}-m>0\right)$. $i$ 's optimal strategy would then not be well defined.

${ }^{31}$ Suppose $F^{\prime}$ 's strategy prescribed $m^{F}=0$ given this history. One step back, if $\mu \in\left(\Delta W, \Delta W^{c, F, E}\right], i$ 's optimal action would be $m=\Delta W^{c, F, E}-\mu+\epsilon$, with $\epsilon>0$ infinitesimally small (it is the cheapest way to trigger $m^{F}=-\Delta W^{F}$ and thus $m^{E}=0$ and $R=0$, and one that yields $-\Delta W^{i}-m>0$ ). $i$ 's optimal strategy would then not be well defined.
} 
both $m=0$ (leading to $R=0$ ) and $m=-\Delta W^{i}$ (leading to $R=1$ ) are optimal actions. If $\mu<\Delta W, i$ 's unique optimal action is $m=0$ (since to have $R=0$ would cost more than $\left.-\Delta W^{i}\right)$. Suppose $\xi<\frac{1-\theta_{i}-\theta_{c}}{2} \gamma$. The proof proceeds in a similar fashion, and is relegated to Online Appendix B5. Having derived the SPE of the subgame that starts after $i$ does not surrender power, consider $i$ 's optimal strategy in Stage 1. If $\mu>\Delta W, i$ 's unique optimal action is not to surrender power (since this leads to $R=0$, at a cost less than $-\Delta W^{i}$ to $i$ ). If $\mu<\Delta W, i$ is indifferent between surrendering power or not (since the latter would lead to $m=0$ and $R=1$ ). By assumption (see Section 2.1), $i$ surrenders power. If $\mu=\Delta W, i$ is again indifferent between surrendering power or not (since the latter would lead to either $m=0$ and $R=1$, or to $m=-\Delta W^{i}$ and $R=0$ ). Again, by assumption, $i$ surrenders power.

QED

\subsection{Proofs.}

Proof to Lemma 1. The proof builds on Proposition A1. The verb "imply" is used as shorthand for "by the strategy described in Proposition A1, imply." Suppose $i$ does not surrender power in $t=1$. Suppose $\xi \geq \frac{1-\theta_{i}-\theta_{c}}{2} \gamma$. If $\underline{\mu>\Delta W^{c, E}}$, it is $\mu>\Delta W^{c, E} \geq$ $\Delta W^{c, F, E}$, implying $m=0$. It is then $\mu>\Delta W^{c, E}-m$, implying $m^{F}=0 ; \mu>\Delta W^{c, E}-m-$ $m^{F}$, implying $m^{E}=0$; and $\mu>\Delta W^{c, E}-m-m^{F}-m^{E} \geq \Delta W^{c}-m-m^{F}-m^{E}$, implying $R=0$. The case $\mu \in\left(\Delta W^{c, F, E}, \Delta W^{c, E}\right]$ only applies if $\Delta W^{F}<0$. It is $\mu>\Delta W^{c, F, E}$, implying $m=0$. It is then $\mu \in\left(\Delta W^{c, F, E}-m, \Delta W^{c, E}-m\right]$, implying $m^{F}=\Delta W^{c, E}-m-$ $\mu=\Delta W^{c, E}-\mu$; and $\mu=\Delta W^{c, E}-m-m^{F}$, implying $m^{E}=0$ (given the history: $m^{F} \in$ $\left.\left[0,-\Delta W^{F}\right)\right)$. As for $c^{\prime}$ 's equilibrium action, if $\Delta W^{E}>0$, it is $\mu>\Delta W^{c}-m-m^{F}-m^{E}$, implying $R=0$; if $\Delta W^{E}=0$, it is $\mu=\Delta W^{c}-m-m^{F}-m^{E}$, implying $R=0$ (given the history: $\left.m^{F} \in\left[0,-\Delta W^{F}\right)\right) . \mu \in\left(\Delta W, \Delta W^{c, F, E}\right]$ implies $m=\Delta W^{c, F, E}-\mu$. It is

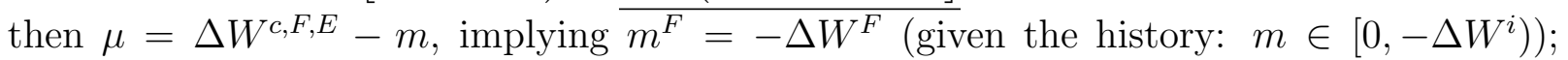
and $\mu=\Delta W^{c, E}-m-m^{F}$, implying $m^{E}=0$ (given the history: $m \in\left[0,-\Delta W^{i}\right.$ ) and $\left.m^{F}=-\Delta W^{F}\right)$. As for c's equilibrium action, if $\Delta W^{E}>0$, it is $\mu>\Delta W^{c}-m-m^{F}-m^{E}$, implying $R=0$; if $\Delta W^{E}=0$, it is $\mu=\Delta W^{c}-m-m^{F}-m^{E}$, implying $R=0$ (given the history: $m \in\left[0,-\Delta W^{i}\right)$ and $\left.m^{F}=-\Delta W^{F}\right) . \mu<\Delta W$ implies $m=0$. It is then

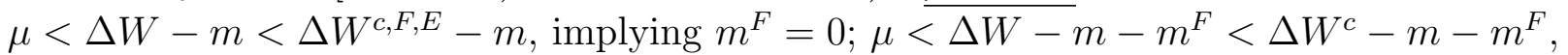
implying $m^{E}=0,{ }^{32}$ and $\mu<\Delta W^{c}-m-m^{F}-m^{E}$, implying $R=1 . \underline{\mu}=\Delta W$ implies that it is either $m=0$ or $m=-\Delta W^{i}$. If $m=0$, the same logic applies as for $\mu<\Delta W$. Suppose instead $m=-\Delta W^{i}$. Clearly, such an action can only be part of an equilibrium in which $E$ sets $m^{E}=0$, and $c$ sets $R=0$. But it must also be $m^{F}=-\Delta W^{F}$ in such an equilibrium. If $\Delta W^{F}=0$, this follows immediately from the fact that $F^{\prime}$ 's strategy must prescribe $m^{F}=0=-\Delta W^{F}$ always. If $\Delta W^{F}<0$, suppose it was $m^{F}<-\Delta W^{F}$. Then, it would be $\mu=\Delta W=\Delta W^{c, F, E}-m<\Delta W^{c, E}-m-m^{F}$. This would imply either $m^{E}>0$ and $R=1$ (if $\mu>\Delta W^{c}-m-m^{F}$ ), or $m^{E}=0$ and $R=1$ (if $\mu \leq \Delta W^{c}-m-m^{F}$ ), a contradiction.

\footnotetext{
${ }^{32}$ Using equations ?? and ??, it is easy to see that $\Delta W^{F, E} \leq 0$ if $\xi \geq \frac{1-\theta_{i}-\theta_{c}}{2} \gamma$. This implies $\Delta W \leq$ $\Delta W^{c, i}<\Delta W^{c}$.
} 
Next, suppose $\xi<\frac{1-\theta_{i}-\theta_{c}}{2} \gamma . \mu>\Delta W^{c, F, E}$ implies $m=0$. It is then $\mu>\Delta W^{c, F, E}-m$, implying $m^{F}=0 ; \mu>\Delta W^{c, F, E-m-m^{F}}>\Delta W^{c}-m-m^{F}$, implying $m^{E}=0,3$ $\mu>\Delta W^{c}-m-m^{F}-m^{E}$, implying $R=0 . \mu \in\left(\Delta W, \Delta W^{c, F, E}\right]$ implies $m=\Delta W^{c, F, E}-\mu$. It is then $\mu=\Delta W^{c, F, E}-m$, implying $m^{\bar{F}}=0$ (given the history: $m \in\left[0,-\Delta W^{i}\right)$ ); $\mu=\Delta W^{c, F, E}-m-m^{F}>\Delta W^{c}-m-m^{F}$, implying $m^{E}=0$; and $\mu>\Delta W^{c}-m-m^{F}-m^{E}$, implying $R=0 . \mu<\Delta W$ implies $m=0$. There are then two cases. First, if $\mu \geq \Delta W^{c, E}$, it is $\mu \geq \Delta W^{c, E}-m$, implying $m^{F}=\Delta W^{c, E}-\mu{ }^{34}$ It is then $\mu=\Delta W^{c, E}-m-m^{F}$, implying $m^{E}=0$ (given the history: $m^{F} \in\left(-\Delta W^{F}, 0\right]$ ). As for $c^{\prime}$ s action, if $\Delta W^{E}<0$, it is $\mu<\Delta W^{c}-m-m^{F}-m^{E}$, implying $R=1$; if $\Delta W^{E}=0$, it is $\mu=\Delta W^{c}-m-m^{F}-m^{E}$, implying $R=1$ (given the history: $m^{F} \in\left(-\Delta W^{F}, 0\right]$ ). Second, if $\mu<\Delta W^{c, E}$, it is $\mu<\Delta W^{c, E}-m$, implying $m^{F}=0$. It is then $\mu<\Delta W^{c, E}-m-m^{F}$, implying $m^{E}=0$; and $\mu<\Delta W^{c, E}-m-m^{F}-m^{E} \leq \Delta W^{c}-m-m^{F}-m^{E}$, implying $R=1 . \mu=\Delta W$ implies that it is either $m=0$ or $m=-\Delta W^{i}$. If $m=0$, the same logic applies as for $\mu<\Delta W$. Suppose $m=-\Delta W^{i}$. Such an action can only be part of an equilibrium in which $F$ sets $m^{F}=0$, and $c$ sets $R=0$. It is then $\mu=\Delta W>\Delta W^{i, c}=\Delta W^{c}-m-m^{F}$, implying $m^{E}=0$ in equilibrium.

QED

Proof to Proposition 1. The proof builds on Proposition A1, and on Lemma 1. By the strategy described in Proposition A1, $i$ surrenders power if $\mu \leq \Delta W$, does not surrender power otherwise. The rest of the Proposition follows immediately from Lemma 1.

QED

${ }^{33}$ Using equations ?? and ??, it is easy to see that $\Delta W^{F, E}>0$ if $\xi<\frac{1-\theta_{i}-\theta_{c}}{2} \gamma$.

${ }^{34}$ It is always $\mu \in\left[\Delta W^{c, E}-m, \Delta W^{c, E, F}-m\right)$ in this case, since $\Delta W<\Delta W^{c, E, F}$. 